\title{
SÍNTESIS DE LOS ESTUDIOS ARQUEOMALACOLÓGICOS EN CONCHEROS DE LA COSTA NORTE DE SANTA CRUZ, PATAGONIA ARGENTINA
}

\section{SYNTHESIS OF ARCHAEOMALACOLOGICAL STUDIES ON SHELL MIDDENS FROM THE NORTHERN COAST OF SANTA CRUZ, ARGENTINE PATAGONIA}

\author{
Heidi Hammond ${ }^{1}$ \\ 1 División Arqueología, Museo de La Plata, Facultad de Ciencias Naturales y Museo, \\ Universidad Nacional de La Plata. Paseo del Bosque S/N, La Plata, Argentina. \\ heidihammondunlp@gmail.com
}

Presentado: 28/11/2018 - Aceptado: 11/04/2019

\section{Resumen}

Se presenta una sintesis de los estudios arqueomalacológicos sobre exoesqueletos de moluscos recuperados en concheros en el área de la costa norte de la provincia de Santa Cruz, Patagonia argentina. Los trabajos se han desarrollado a partir de una perspectiva arqueológica regional en la cual se han implementado prospecciones intensivas para el registro de concheros, complementadas con excavaciones estratigráficas, las cuales han permitido obtener muestras representativas de los depósitos, y a su vez, comparables entre sí. Los estudios arqueomalacológicos involucraron la identificación anatómica y taxonómica de los restos, su cuantificación, la evaluación del estado de conservación, estudios biométricos y la identificación de los procesos tafonómicos que han afectado a los exoesqueletos. Fue posible identificar a las especies seleccionadas por los grupos humanos como alimento, los principales procesos de formación de los concheros y un posible proceso de intensificación en la explotación del recurso malacológico en el sector sur del área durante el Holoceno tardío. Las diferentes líneas de trabajo han aportado información para conocer diversas características del pasado humano relacionadas con la subsistencia, las conductas de recolección y los modos de ocupación del espacio. Además, han permitido discutir aspectos paleoambientales, tafonómicos y tecnológicos.

Palabras clave: Arqueomalacología, Concheros, Exoesqueletos de moluscos, Cazadoresrecolectores, Tafonomía, Costa norte de Santa Cruz

\begin{abstract}
A synthesis of archaeomalacological studies on exoskeletons of molluscs recovered in shell middens on the northern coast of Santa Cruz province, Argentine Patagonia is presented. The research have been developed from a regional perspective in which intensive surveys have been implemented to study of the record of shell middens complemented with stratigraphic excavations, which have allowed to obtain representative and comparable samples of the deposits. The archaeomalacological studies involved the anatomical and taxonomic identification of the remains, its quantification, and the evaluation of conservation characteristics, biometric studies and the identification of taphonomic processes that have affected the exoskeletons. It was possible to identify the species selected by the human groups as food, the main processes of site formation of the shell middens and a
\end{abstract}


possible process of intensification in the exploitation of the malacological resource in the southern sector of the area during the late Holocene. The different lines of work have provided information on subsistence, gathering behavior and modes of space occupation. They have also allowed discussing paleoenvironmental, taphonomic and technological issues.

Keywords: Archaeomalacology, Shell middens, Mollusk exoskeletons, Hunter-gatherers; Taphonomy, Northern coast of Santa Cruz

\section{Introducción}

Las poblaciones humanas que habitaron en el pasado el área de la costa norte de la provincia de Santa Cruz (en adelante CNSC) (Figura 1) hicieron un uso intenso de los recursos, tanto terrestres como marinos, disponibles en las costas y en el interior del territorio. La explotación de moluscos fue una actividad importante en la obtención de alimentos; además, las aves marinas y los pinnípedos también representaron un aporte fundamental a las dietas durante el Holoceno (Beretta et al. 2011, Moreno et al. 2011, Zilio et al. 2014, 2018a). Los concheros son uno de los tipos de registros arqueológicos más representados en el área de estudio, se hallan distribuidos a lo largo del paisaje, principalmente en cercanías del litoral marítimo (Castro et al. 2001, 2003, Zubimendi 2010, Hammond et al. 2013, Hammond 2015, 2018, Hammond y Zilio 2018). Estos sitios están conformados especialmente por exoesqueletos de moluscos y proporciones variables de matriz sedimentaria, en asociación con diferentes materiales arqueológicos como restos de vertebrados (pinnípedos, aves marinas, peces, guanacos, armadillos, entre otros), artefactos líticos y carbón vegetal (Hammond 2015). Los concheros han sido interpretados como áreas de actividades múltiples, en las que se habrían desarrollado diferentes tareas cotidianas relacionadas con la subsistencia, el procesamiento de recursos alimenticios y de materias primas, la manufactura y el mantenimiento de artefactos, entre otras (Hammond 2015).

El objetivo de este trabajo es a partir de diferentes líneas de estudio arqueomalacológicas de conjuntos de concheros que se desarrollaron para el área de la CNSC, discutir los aportes de estas aproximaciones al conocimiento de las poblaciones humanas pasadas, las especies de importancia para la subsistencia, las conductas de recolección y los modos de ocupación del espacio. Además, se evalúan los procesos de formación de los concheros, aspectos paleoambientales, tafonómicos y tecnológicos. 


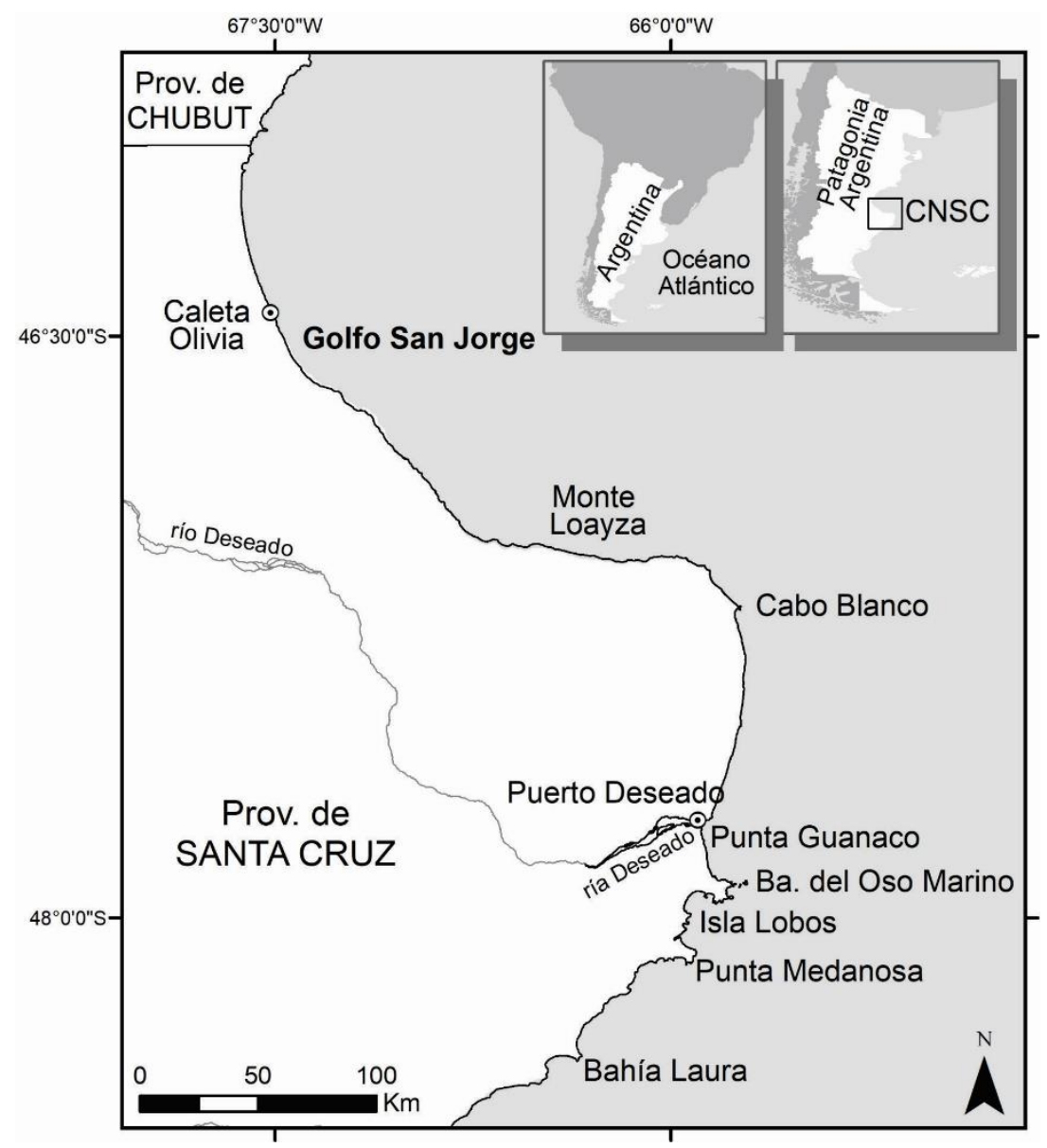

Figura 1. Ubicación del área de estudio de la costa norte de Santa Cruz y localidades mencionadas en el texto.

A partir de las investigaciones arqueomalacológicas realizadas en los últimos años (Hammond 2014, 2015, 2018, Hammond et al. 2009, 2013, 2016, Hammond y Zilio 2016a y b, 2017, 2018, Hammond y Ciampagna 2019, Zubimendi 2012) se han analizado los restos de moluscos recuperados en contextos arqueológicos, ya sea como elementos aislados o como acumulaciones (Claassen 1998, Gutiérrez Zugasti 2008a, Serrand et al. 2008, Bejega García et al. 2010). A través del estudio de los diferentes elementos diagnósticos de los exoesqueletos de moluscos y aplicando diversas metodologías analíticas, es posible conocer aspectos de la vida de las sociedades del pasado, así como los agentes y procesos involucrados en la formación de los depósitos arqueológicos (Claassen 1998, Chaix y Méniel 2005).

El estudio de las ocupaciones humanas en concheros de la CNSC se ha desarrollado a partir de una perspectiva arqueológica regional en la cual se han implementado prospecciones intensivas con el fin de evaluar la distribución de las evidencia a lo largo del paisaje, las características del emplazamiento de los sitios y la relación con zonas con disponibilidad de recursos, e identificar los procesos y los agentes tafonómicos presentes a lo largo del área costera. 
Los estudios arqueomalacológicos en la CNSC se iniciaron con la identificación de las especies de moluscos reconocidas en sitios arqueológicos superficiales (Castro et al. 2003, Zubimendi et al. 2004, 2005). Años más tarde comenzó la investigación sistemática de conjuntos malacológicos procedentes de concheros (Figura 2) junto con excavaciones que permitieron analizar los materiales que componen este tipo de registro, los procesos de formación de los sitios, obtener cronologías de las ocupaciones humanas y contar con muestras arqueomalacológicas representativas y comparables (Zubimendi 2012, Hammond 2014, 2015, Hammond y Zilio 2016a, 2017, entre otros). Estos estudios involucraron además observaciones de fauna malacológica actual, así como análisis experimentales controlados que han permitido discutir la acción de posibles agentes y de modificaciones registradas en los restos arqueológicos (Hammond y Zilio 2016b, Hammond y Ciampagna 2019).
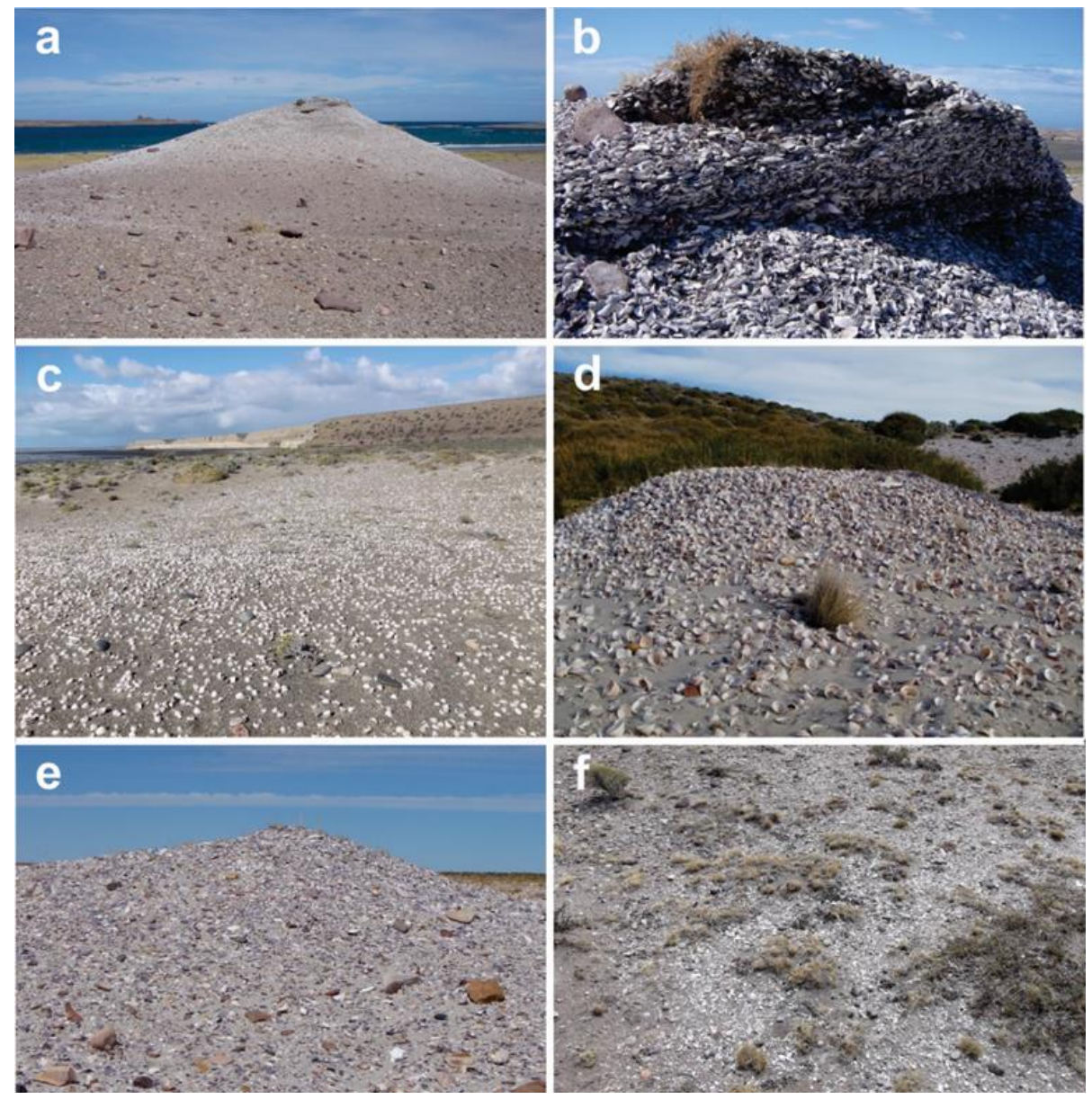

Figura 2. Vista de concheros en la CNSC. a y b. Localidad Isla Lobos. c. Localidad Punta Guanaco. d y e. Localidad Bahía del Oso Marino. f. Margen sur de la ría Deseado.

El ambiente y la malacofauna en el área de estudio

En la actualidad el clima en la CNSC es árido a semiárido y ventoso, con escasas precipitaciones, marcadas amplitudes térmicas diarias, fuerte evaporación y vegetación de tipo estepario. El sector de costa muestra una importante variabilidad geomorfológica en las formas del paisaje, caracterizado por una secuencia de geoformas de erosión y 
depositación que dan origen a una costa recortada en la que se alternan salientes, formadas por rocas resistentes al embate erosivo de las olas, y caletas, donde la acumulación de los materiales trasportados por las corrientes litorales han formado crestas de playa (cordones litorales) (Mazzoni 2000). En líneas generales estas son costas erosivas, con desarrollo de acantilados activos. Entre las formas de acumulación marina predominan las playas de grava y ocasionalmente aquellas de arena (Codignotto 1997).

Las especies de moluscos presentes en las costas forman parte de la Provincia Biogeográfica Magallánica. Esta se extiende desde Península Valdés - Golfo Nuevo $\left(43^{\circ} \mathrm{S}\right)$ hasta el extremo sur del continente en el Cabo de Hornos (55'S) (Aguirre 2003; Balech y Ehrlich 2008). Gordillo (1998) señala que la Provincia Magallánica está definida por la presencia de una serie de especies malacológicas específicas: Perumytilus purpuratus, Mytilus edulis, Aulacomya atra, Ameghinomya antiqua, Nacella magellanica y Pareuthria fuscata. Aguirre y Farinati (2000) agregan los venéridos Eurhomalea exalbida y Tawera elliptica. En la Provincia Magallánica se da un predominio de especies epifaunales como una adaptación al litoral rocoso que caracteriza a la región (Gordillo 1998). En las Figuras 3 y 4 se presentan las principales especies de gasterópodos y bivalvos identificadas en la CNSC.

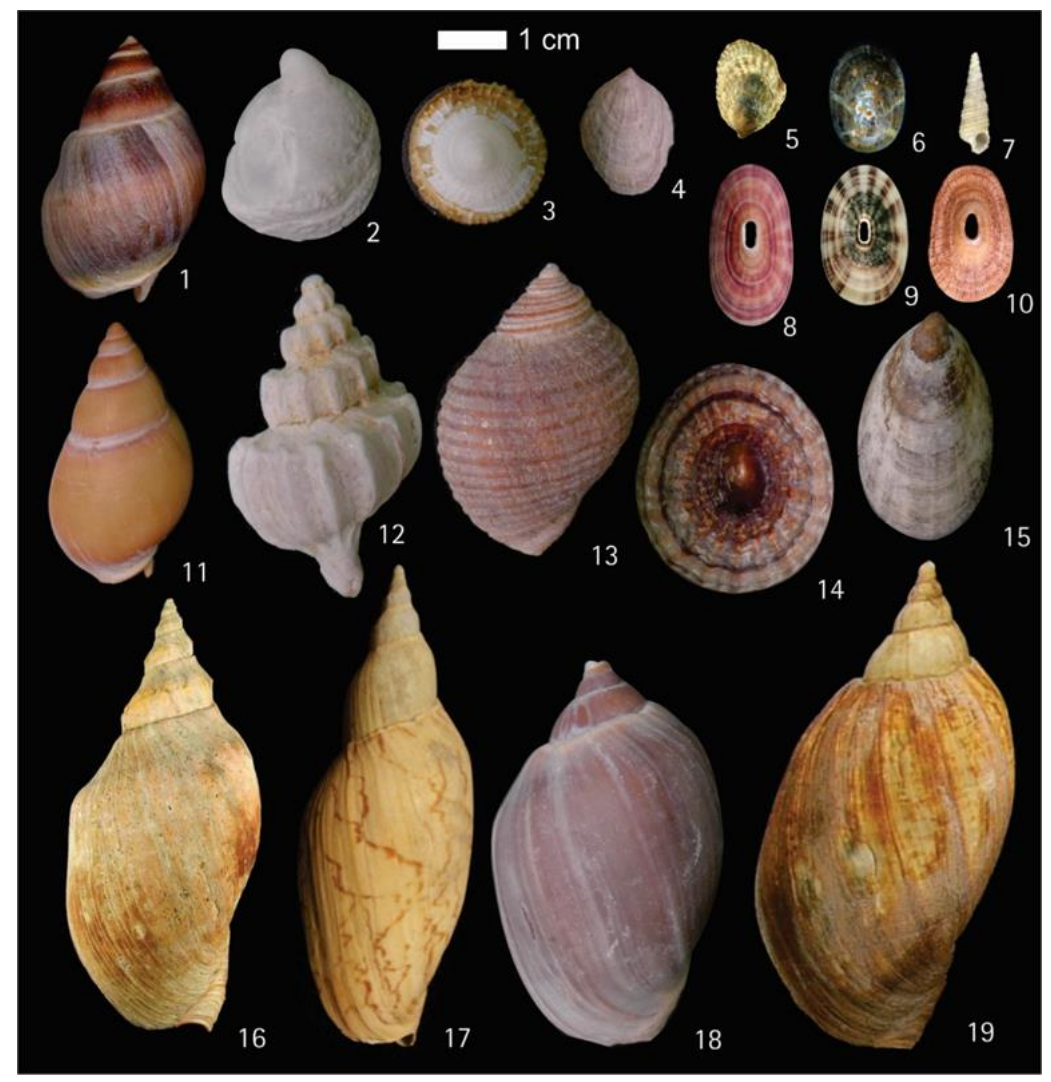

Figura 3. Taxones de Gasterópodos característicos en contextos arqueológicos en la CNSC. 1. Buccinanops deformis. 2. Crepipatella dilatata. 3. Trochita pileus. 4. Siphonaria lessoni. 5. Siphonaria lateralis. 6. Iothia emarginuloides. 7. Eumetula pulla. 8. Fissurella oriens. 9. Fissurella picta. 10. Lucapinella henseli. 11. Pareuthria fuscata. 12. Trophon geversianus. 13. Acanthina monodon. 14. Nacella magellanica. 15. Nacella mytilina. 16. Adelomelon beckii. 17. Adelomelon ancilla. 18. Adelomelon ferussaci. 19. Odontocymbiola magellanica. 
Los estudios paleobiogeográficos desarrollados en el área plantean que las especies de moluscos presentes no habrían variado significativamente a lo largo del Holoceno (Aguirre 2003, Aguirre et al. 2009, Medina et al. 2014). Ecológicamente, la estructura poblacional de los moluscos en las costas se habría mantenido estable a través del tiempo. En estudios geomorfológicos y de composición biogénica de las geoformas costeras en la localidad Punta Medanosa, Medina y colaboradores (2014) plantearon que existen escasas variaciones composicionales a nivel de los taxones de moluscos presentes entre los cordones holocenos y el litoral moderno vecino. Los paleoambientes (litorales someros, de fondos fundamentalmente blandos y aguas frías de baja energía) inferidos para el lapso Holoceno medio-tardío no difieren mayormente del litoral moderno adyacente, sugiriendo una rápida transición hasta el presente y con escasos cambios desde ca. 6000 AP.

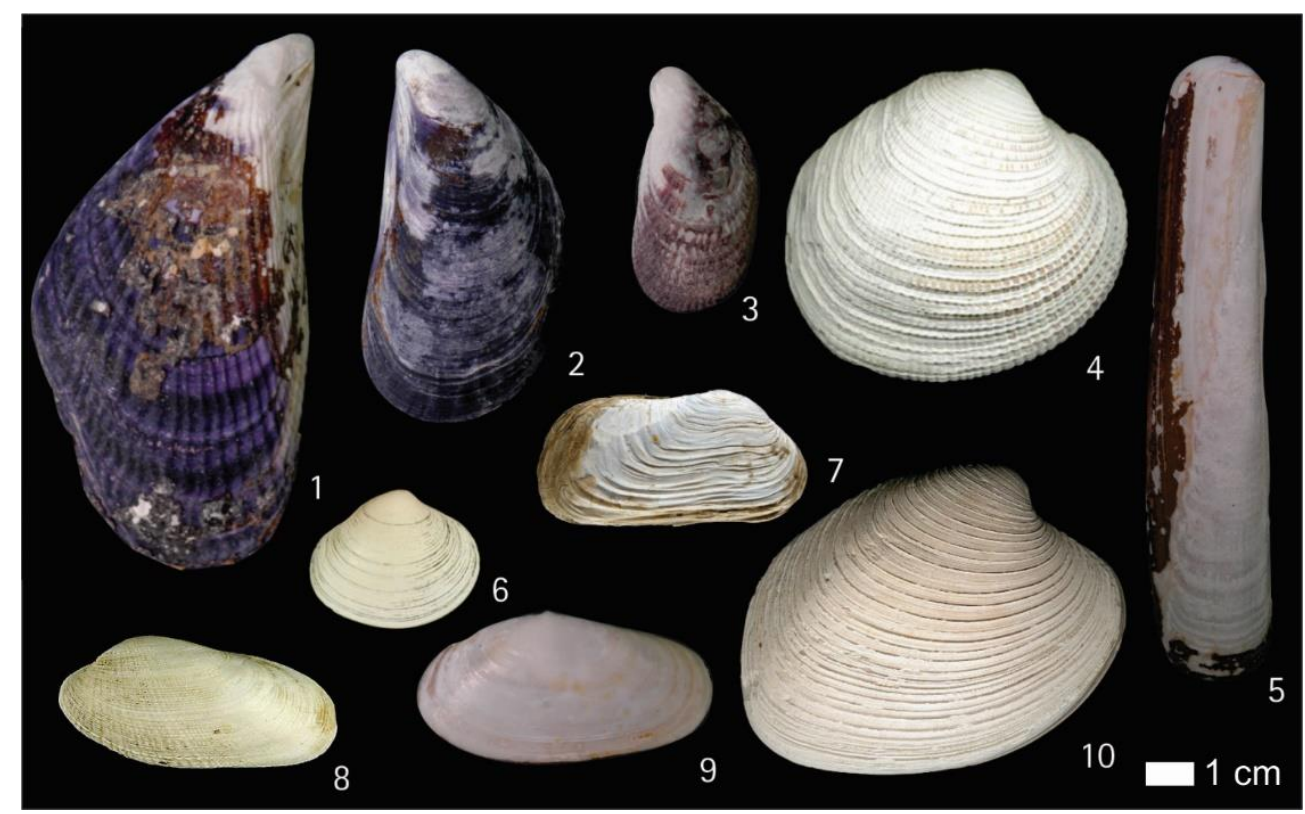

Figura 4. Taxones de Bivalvos característicos en contextos arqueológicos en la CNSC. 1.

Aulacomya atra. 2. Mytilus edulis. 3. Perumytilus purpuratus. 4. Ameghinomya antiqua. 5. Ensis macha. 6. Tawera elliptica. 7. Hiatella arctica. 8. Petricola dactylus. 9. Darina solenoides. 10. Eurhomalea exalbida.

\section{Materiales y métodos}

Se desarrollaron estudios distribucionales a partir de los cuales se registró la presencia de concheros a lo largo de cinco localidades arqueológicas de la CNSC y de un sector lagunar a $20 \mathrm{~km}$ al norte de la ciudad de Puerto Deseado (Figura 1). A partir de la aproximación distribucional mediante la metodología de registro y análisis de concheros especificada en Hammond (2015) se buscó indagar acerca de la existencia de posibles condicionantes sobre la distribución de los sitios en el espacio (por ejemplo, cercanía a plataformas de abrasión con presencia de moluscos, sustratos de ocupación disponibles, cercanía o disponibilidad de agua dulce, entre otras), analizar la geomorfología de las zonas donde se emplazan los concheros, evaluar los efectos de los procesos de formación del registro y las 
condiciones de preservación de los exoesqueletos de moluscos en superficie para comparar esa información con los registros estratigráficos y reconocer características específicas acerca de la morfología y la estructura de los sitios.

Por otro lado, a partir de excavaciones sistemáticas se obtuvieron conjuntos malacológicos. La recuperación de los materiales se realizó utilizando una malla de zaranda de $2 \mathrm{~mm}$ de apertura adecuada para una recuperación del material que sea representativa y que permita una fiable interpretación de los datos (Claassen 1998). Se recolectó la totalidad de los "fondos de zaranda", que fueron analizados más tarde en laboratorio, tarea que permitió identificar diversos restos arqueológicos pequeños que conforman los depósitos.

\begin{tabular}{|c|c|c|c|c|c|c|}
\hline \multirow[t]{2}{*}{ Localidad } & \multirow[t]{2}{*}{ Sitio } & \multirow{2}{*}{$\begin{array}{c}\text { Superficie } \\
\text { excavada } \\
\left(\mathrm{m}^{2}\right)\end{array}$} & \multicolumn{2}{|c|}{$\begin{array}{c}\text { Exoesqueletos } \\
\text { de moluscos }\end{array}$} & \multirow{2}{*}{$\begin{array}{c}\text { Densidad de } \\
\text { moluscos } \\
\left(\mathrm{NR} / \mathrm{dm}^{3}\right)\end{array}$} & \multirow{2}{*}{$\begin{array}{l}\text { Datación } \\
\text { radiocarbónica* }^{*}\end{array}$} \\
\hline & & & NR & NMI & & \\
\hline $\begin{array}{l}\text { Ría Deseado } \\
\text { Margen sur }\end{array}$ & $\begin{array}{l}\text { Puerto Jenkins } \\
2\end{array}$ & 0,5 & 4.347 & 3.527 & 37,8 & $\begin{array}{l}690 \pm 60 \mathrm{AP} ; \\
\mathrm{LP}-2603\end{array}$ \\
\hline \multirow{3}{*}{$\begin{array}{l}\text { Puerto } \\
\text { Deseado }\end{array}$} & La Escondida & 1 & 264 & 264 & 4,4 & $\begin{array}{l}920 \pm 50 \mathrm{AP} ; \\
\mathrm{LP}-3359\end{array}$ \\
\hline & El Pajonal & 1 & 179 & 179 & 1,8 & - \\
\hline & UNPA & 7,25 & 9.050 & 6.330 & $\begin{array}{c}\text { Entre } 6,5 \mathrm{y} \\
30,5\end{array}$ & $\begin{array}{l}970 \pm 50 \mathrm{AP} ; \mathrm{LP}-2891 \\
690 \pm 70 \mathrm{AP} ; \mathrm{LP}-2896\end{array}$ \\
\hline \multirow{2}{*}{$\begin{array}{l}\text { Bahía del } \\
\text { Oso Marino }\end{array}$} & $\begin{array}{l}\text { Playa del } \\
\text { Negro }\end{array}$ & 0,5 & 2.967 & 2.116 & 14,1 & $\begin{array}{l}1.450 \pm 60 \mathrm{AP} \\
\mathrm{LP}-2682\end{array}$ \\
\hline & Las Hormigas & 1 & 4.529 & 2.698 & 15,1 & $\begin{array}{l}370 \pm 40 \mathrm{AP} \\
\mathrm{LP}-2504\end{array}$ \\
\hline Isla Lobos & Sitio 112 & 0,25 & 1.091 & 602 & 31,2 & $\begin{array}{l}2.870 \pm 60 \mathrm{AP} \\
\mathrm{LP}-2141\end{array}$ \\
\hline \multirow{8}{*}{$\begin{array}{l}\text { Punta } \\
\text { Medanosa }\end{array}$} & $\begin{array}{l}\text { Sitio } 160 \\
\text { (sondeo 1) }\end{array}$ & 0,25 & 1.704 & 1.045 & 18,9 & $\begin{array}{l}370 \pm 50 \mathrm{AP} \\
\mathrm{LP}-2507\end{array}$ \\
\hline & $\begin{array}{l}\text { Sitio } 160 \\
\text { (sondeo 2) }\end{array}$ & 0,25 & 1.238 & 842 & 55 & $\begin{array}{l}1.260 \pm 80 \mathrm{AP} \\
\mathrm{LP}-3091\end{array}$ \\
\hline & Médano 1 & 0,25 & 4.658 & 2.823 & 49,1 & $\begin{array}{l}2.140 \pm 60 \mathrm{AP} \\
\mathrm{LP}-2501\end{array}$ \\
\hline & $\begin{array}{l}\text { Punta Buque } 1 \\
\text { (sondeo 1) }\end{array}$ & 0,25 & 435 & 351 & 8,3 & $\begin{array}{l}1.070 \pm 60 \mathrm{AP} \\
\mathrm{LP}-2724\end{array}$ \\
\hline & $\begin{array}{l}\text { Punta Buque } 1 \\
\text { (sondeo 2) }\end{array}$ & 0,25 & 4.649 & 3.323 & 47,7 & $\begin{array}{l}1.720 \pm 100 \mathrm{AP} \\
\mathrm{LP}-3099\end{array}$ \\
\hline & Puesto Baliza 1 & 0,25 & 295 & 231 & 2,9 & - \\
\hline & $\begin{array}{l}\text { Puesto Baliza } 2 \\
\text { (sondeo 1) }\end{array}$ & 0,25 & 1.116 & 755 & 11,4 & - \\
\hline & $\begin{array}{l}\text { Puesto Baliza } 2 \\
\text { (sondeo 2) }\end{array}$ & 0,25 & 1.753 & 1.220 & 17,5 & $\begin{array}{l}1.290 \pm 60 \mathrm{AP} ; \\
\mathrm{LP}-2732\end{array}$ \\
\hline
\end{tabular}

Tabla 1. Concheros excavados en la CNSC de los cuales se cuenta con datos arqueomalacológicos cuantitativos, taxonómicos, tafonómicos y biométricos. ${ }^{*}$ En todos los casos el material datado corresponde a carbón vegetal.

El estudio de los restos arqueomalacológicos se llevó a cabo por un lado a partir de una perspectiva "individual" y por otro lado se analizó cada sitio como un "todo", con especial énfasis en su principal componente que corresponde a los exoesqueletos de moluscos (Gutiérrez Zugasti 2008a). 
A nivel "individual" se analizaron todos los exoesqueletos de moluscos obtenidos de excavaciones sistemáticas a partir de la metodología arqueomalacológica detallada en Hammond (2015). En la Tabla 1 se presenta una síntesis de los concheros excavados de los cuales se obtuvieron conjuntos arqueomalacológicos para la realización de análisis cuantitativos, taxonómicos, tafonómicos y biométricos.

Se realizó la identificación anatómica y taxonómica de los exoesqueletos que conforman las muestras. Se llevó a cabo la cualificación (Número de restos -NR- y el Número mínimo de individuos -NMI-) teniendo en cuenta categorías de fragmentación de las conchas y la terminología sugerida por Gutiérrez Zugasti (2008b) y Álvarez Fernández (2009): ICOM-VCOM (individuo completo -gasterópodos- y valva completa -bivalvos-, restos que conservan más del 90\% de la concha completa y el elemento diagnóstico individual o Elemento no Repetitivo, Mason et al. 1998); IFRA-VFRA (individuo fragmentado y valva fragmentada; fragmentos que conservan menos del 90\% del exoesqueleto y el elemento diagnóstico individual), FAPI-FCHC (fragmento de ápice y fragmento de charnela) y FRAG (fragmentos de conchas sin elementos diagnósticos para su identificación taxonómica y cuantificación).

Se relevaron las medidas biométricas de las conchas completas de las cuatro especies más representadas en los sitios arqueológicos -Nacella magellanica, Mytilus edulis, Aulacomya atra y Perumytilus purpuratus- (Figura 5), y además se indagó acerca del peso como estimador de abundancia de los restos, especialmente para el caso de los fragmentos con ausencia de elementos diagnóstico para su determinación taxonómica (Hammond 2015).

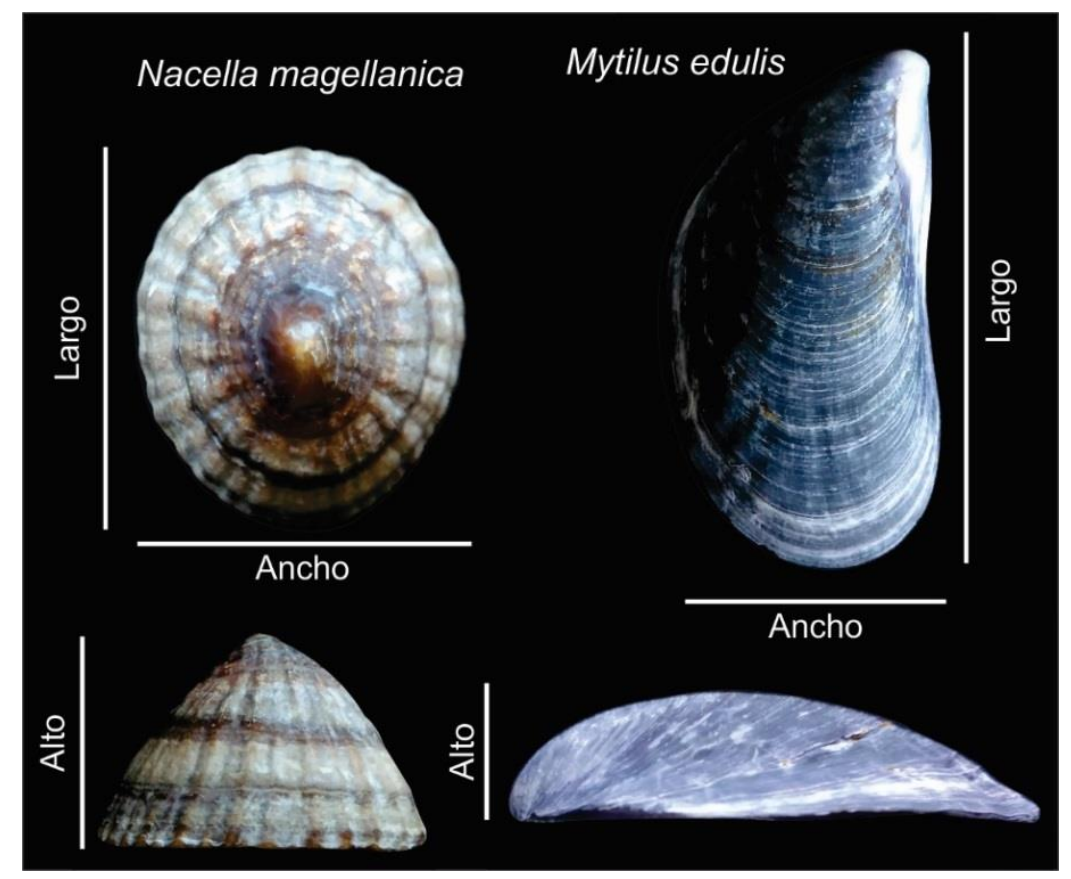

Figura 5. Medidas de tamaño de los exoesqueletos. Izquierda: Nacella magellanica. Derecha: valva derecha de Mytilus edulis. 
Las variables tafonómicas y de preservación de los exoesqueletos individuales de moluscos que se analizaron fueron: la preservación del periostraco, las evidencias de corrosión, abrasión, fragmentación, bioerosión (incrustaciones y perforaciones), signos de alteración térmica, presencia de roturas y/o signos de impacto en conchas de Nacella magellanica, marcas y la preservación del color original.

En el análisis de los depósitos de conchero como un "todo", se contempló que diferentes procesos naturales y antrópicos pueden crear y alterar los sitios conformados por restos de moluscos. El efecto de estos procesos puede producir depósitos promediados temporalmente (Claassen 1998). Los concheros emplazados cercanos a la línea de costa, deben ser analizados cuidadosamente debido a que las mareas en ocasiones pueden producir la remoción y redepositación de los materiales arqueológicos, así como la mezcla con materiales modernos transportados por las olas. Los análisis tafonómicos de los exoesqueletos son en este caso una herramienta útil para poder discriminar esta clase de materiales y analizar los procesos que han sufrido. Entre los procesos tafonómicos que pueden afectar a los depósitos de conchero como un todo se consideró la acción de desplazamientos (remoción, redepositación y reorientación), los efectos de la erosión costera y de la cementación-carbonatación de los materiales generada por adición de componentes minerales.

En el análisis de la estructura de los concheros, referida al patrón de distribución de los materiales con especial atención en los exoesqueletos de moluscos, se consideró la geometría y la fábrica de los mismos (Kidwell y Holland 1991, Favier Dubois y Borella 2007). Los depósitos pueden presentar geometrías lenticulares, tabulares y tabulares masivas, con variaciones en la densidad de restos arqueomalacológicos. Los depósitos lenticulares poseen mayor espesor en el centro y se afinan hacia los bordes convexos; los tabulares presentan espesor relativamente homogéneo, con un desarrollo horizontal significativamente mayor que su extensión vertical; cuando las acumulaciones de alta densidad de materiales poseen más de $30 \mathrm{~cm}$ de espesor, la geometría se distingue como tabular masiva. En cuanto a la fábrica o el arreglo interno de los exoesqueletos de los moluscos, los dos tipos básicos identificados son: clasto sostenida (bioclastos) y matriz sostenida (Hammond, 2015, Hammond et al. 2016). A su vez, estos tipos pueden presentar variación en cuanto a su compactación, el tamaño y la densidad de los bioclastos en la matriz sedimentaria, su orientación, consistencia y la distribución de los mismos (Kidwell y Holland 1991).

En relación a los conjuntos estratigráficos se evaluaron también variables del ambiente de depositación como el nivel de $\mathrm{pH}$ por colorimetría y el contenido de materia orgánica a partir del método de Walkley-Black (Allison 1965). 


\section{Resultados y discusión}

Especies malacológicas en concheros de la CNSC

Las evidencias arqueológicas disponibles para el área de la CNSC indican que los recursos malacológicos que componen los concheros fueron aprovechados intensivamente por las poblaciones pasadas (Castro et al. 2003, Zubimendi 2012, Hammond 2015, Zilio et al. 2014, 2018a, entre otros). La explotación de los moluscos en el área ha sido identificada desde el Holoceno medio hasta momentos tardíos (Ambrústolo et al. 2011, Hammond 2015, entre otros). Los concheros se distribuyen principalmente en las localidades arqueológicas adyacentes al litoral atlántico aunque también se identifican en las costas del estuario de la ría Deseado y en las márgenes de lagunas interiores (Hammond 2018, Hammond y Zilio 2018).

En los trabajos distribucionales se relevó una superficie total de $591.100 \mathrm{~m}^{2}$ en las localidades arqueológicas Monte Loayza, ría Deseado, Punta Guanaco, Bahía del Oso Marino y Punta Medanosa (Figura 1), en las cuales se identificó un total de 285 concheros (Hammond 2015). A partir del análisis de los restos malacológicos identificados en los sitios superficiales se observó en general un predominio de las especies Nacella magellanica, Mytilus edulis y Aulacomya atra (Figuras 3 y 4). La predominancia de una u otra especie en los sitios, respondería a un patrón espacial relacionado con la disponibilidad de determinadas especies de moluscos en los intermareales a lo largo del litoral marítimo. De esta manera, en cada una de las localidades se habrían explotado y consumido las especies de moluscos principales disponibles en los intermareales cercanos.

Además, en un sector pericostero ubicado aproximadamente a $20 \mathrm{~km}$ al norte de la ciudad de Puerto Deseado, que se caracteriza por la presencia de ocho cuerpos lagunares endorreicos con contenido ocasional de agua aportado por las lluvias y la escorrentía superficial, se prospectó la totalidad del perímetro de las lagunas y se identificaron 123 sitios representados por acumulaciones con morfología plano extendida, conformadas principalmente por exoesqueletos de la especie Nacella magellanica, restos óseos faunísticos y artefactos líticos (Hammond y Zilio 2018).

A partir de los análisis espaciales se planteó la existencia de un patrón distribucional de concheros en la CNSC. Este patrón se define por la asociación entre los espacios donde se ubican de los sitios y su cercanía a costas de baja pendiente, con presencia de plataformas de abrasión con disponibilidad de moluscos (mesolitorales rocosos y/o arenosos) y de otros recursos marinos, como por ejemplo, pinnípedos, aves y peces (Hammond 2018).

Tanto a partir de los estudios distribucionales en los que se analizó la presencia de especies malacológicas en concheros a lo largo de la CNSC, así como de las excavaciones estratigráficas en las que se cuenta con información cuantitativa de las especies presentes 
(Moreno 2008, Castro et al. 2010, Ambrústolo et al. 2011, Zubimendi et al. 2009, 2010, 2011, Zubimendi 2012, Ambrústolo y Ciampagna 2015, Hammond 2015, 2018, Hammond y Zilio 2017, 2018), se establece que son cuatro las especies malacológicas más abundantes en la mayoría de los contextos: Nacella magellanica, entre los gasterópodos y Mytilus edulis, Aulacomya atra y Perumytilus purpuratus, entre los bivalvos. Otras especies de moluscos se registran siempre en bajas frecuencias (tales como Kerguellenella lateralis, Crepipatella dilatata, Pareutrhia fuscata, Trophon geversianus, Ensis macha) y algunas, sólo en ocasiones (por ejemplo, Epitonium magellanicum o Petricolaria patagonica) (Figura 3 y 4). La similitud en la conformación arqueomalacológica de los conjuntos refuerza la idea de que el tiempo y el espacio promediado, producen conjuntos arqueológicos que reflejan en cierta medida el medio ambiente acuático pasado (Peacock 2000).

Tres son las especies de moluscos identificadas con mayor valor alimenticio que habrían sido seleccionadas y recolectadas en los intermareales costeros de la CNSC (Zubimendi et al. 2004, Zubimendi 2012, Hammond 2015, entre otros). Las especies son Nacella magellanica, Mytilus edulis y Aulacomya atra (Figura 3 y 4). Estas fueron seleccionadas por las poblaciones pasadas, probablemente ya que se presentaban como las más predictibles, en concentraciones cercanas a la costa, accesibles en el intermareal y debido al mayor contenido cárnico en relación a la oferta de moluscos disponibles. Además, podrían haber sido especies seleccionadas también por sus características de palatabilidad o debido a sus relativamente bajas fluctuaciones en cantidades a lo largo del año (estabilidad). Estos recursos pueden ser recolectados por todos los integrantes de la sociedad, tanto ancianos, niños, mujeres y hombres, sin requerir para su obtención el empleo de instrumentos especializados (Yesner 1980, 1983, Waselkov 1987, Erlandson 1988, Claassen 1998).

Las especies Nacella magellanica, Mytilus edulis y Aulacomya atra se desarrollan en los intermareales de sustratos duros o plataformas de abrasión rocosas. En el área de estudio, las zonas de recolección habrían estado situadas en sectores expuestos de la costa abierta, donde durante las mareas bajas comunes es posible recolectar individuos de las especies de moluscos mencionadas que quedan expuestos en el sector superior y medio del intermareal. Otra de las zonas de recolección se situó en la cuenca inferior del estuario de la ría Deseado, donde resalta la presencia del mejillinar y los bancos de Aulacomya atra (Zaixso y Boraso de Zaixso 2013).

En el estudio de los conjuntos malacológicos se han identificado diferentes especies que pueden ser caracterizadas como "acompañantes" de las especies principales o de aquellas seleccionadas por los grupos humanos para el consumo. Las especies de moluscos "acompañantes" presentan tamaños pequeños, comúnmente menores a $3 \mathrm{~cm}$, y en general se hallan adheridas o son epibiontes de las especies recolectadas para ser utilizadas como alimento, por lo que su introducción a los sitios habría sido no intencional (Orquera y Piana 1999, 2000). La presencia abundante de este tipo de moluscos en el registro arqueológico evidencia que las especies principales fueron recolectadas sin una selección individual. Un ejemplo corresponde a las recolecciones en racimos de mitílidos, los cuales 
se encuentran unidos entre sí por el biso o filamento natural que desarrollan estos moluscos para adherirse a las rocas, y que al recolectarlos manualmente "en racimo" se obtiene una gran cantidad de ejemplares junto con otras especies de moluscos más pequeñas que viven en asociación a los mitílidos en las plataformas de abrasión o son epibiontes de los bivalvos (Jones y Richman 1995, Orquera y Piana 1999). En la CNSC, las especies que pueden ser mencionadas como "acompañantes" son: Crepipatella dilatata, Trochita pileus, Pareuthria fuscata, Trophon geversianus, Iothia emarginuloides, Siphonaria lessoni y Siphonaria lateralis (Figura 3).

Además diversas especies de moluscos como murícidos (por ejemplo Trophon geversianus o Buccinanops deformis; Figura 3) y volútidos, actúan muchas veces como predadoras y pueden ser consideradas como fauna acompañante (Lasta et al. 1998). De esta manera, el análisis de la fauna "acompañante" puede aportar información indirecta sobre las técnicas de recolección, así como de las condiciones ecológicas de los sectores en donde fueron recolectados los moluscos seleccionados por los grupos humanos. En los conjuntos estudiados se reconoció una muy baja frecuencia de restos modificados por organismos predatorios o con presencia de incrustaciones (Hammond 2015, Hammond y Zilio 2017). En el caso de las conchas afectadas por organismos bioerosionadores, las perforaciones exitosas en las conchas permiten inferir que estas fueron modificadas por organismos predatorios y por lo tanto pudieron ingresar al sitio sin presencia de carne (Claassen 1998). Las incrustaciones identificadas en restos arqueomalacológicos del área corresponden a pequeños tubos carbonáticos de gusanos poliquetos y restos carbonáticos de algas (por ejemplo, algas con esqueletos calcáreos duros del género Corallina). Estos organismos pueden generar la remoción del periostraco y producir marcas sobre la superficie del exoesqueleto al que se hallan adheridos (Claassen 1998).

Un hecho a tener en cuenta y que ha sido evaluado por otros autores (Ford 1992, Claassen 1998, Campbell 2007, Giovas 2009, Thomas et al. 2017, entre otros), es el análisis de los fragmentos de exoesqueletos de moluscos no identificables recuperados en las excavaciones arqueológicas. En nuestro caso una de las herramientas metodológicas que hemos implementado para la valoración de este tipo de materiales es la aplicación del peso de los restos como estimador de abundancia. Esta es una medida absoluta y consiste en pesar todos los restos de una misma especie que se hallan en la unidad de excavación analizada. El cálculo del peso de los restos arqueomalacológicos es una variable que ha sido discutida por diversos autores (Claassen 1998, 2000, Glassow 2000, Mason et al. 1998, 2000). Una de las principales críticas a este cálculo es que no se consideran los procesos de diagénesis que pueden afectar de forma diferencial al peso de las conchas de distintas especies de moluscos (Claassen 1998, Álvarez Fernández 2009). Otros investigadores plantean que a pesar de las limitaciones que presenta como estimador de abundancia, los valores de peso son importantes puesto que pueden reflejar cambios en la composición de los diferentes niveles de un depósito arqueológico. Del mismo modo, si la muestra exhibe un alto grado de fragmentación, el peso es en ocasiones el único indicador que podemos aplicar durante el muestreo (Bejega García 2008). 
En la CNSC el peso como estimador de abundancia de los fragmentos de exoesqueletos no identificables se aplicó por ejemplo en el conchero UNPA. Este sitio se emplaza en un cordón litoral sobre la margen norte de la ría Deseado, en el ejido urbano de la ciudad de Puerto Deseado (Hammond y Zilio 2017). Se llevó a cabo una excavación en extensión de 7,25 $\mathrm{m}^{2}$ en la cual se muestreó y analizó los restos arqueomalacológicos ubicados en uno de los cuadrantes de $0,25 \mathrm{~m}^{2}$ de cada cuadrícula y los restos de un sondeo (ocho muestras). En este sitio se recuperó un total de restos identificables de moluscos de 9.050 y se determinó un NMI de 6.330, entre los que predominan las conchas de Nacella magellanica. En la Figura 5 se presenta un gráfico comparativo que muestra el uso del peso como estimador de abundancia de los restos. Se contempla el peso de los restos que conforman las muestras según las diferentes categorías de fragmentación para las clases Gasterópodos y Bivalvos (ICOM-VCOM; IFRA-VFRA; FAPI-FCHC y FRAG). Se observa que en todas las muestras $(\mathrm{M})$ y en el sondeo (S) predominan los fragmentos de conchas no identificables (FRAG). Sin embargo, en las M3, 4 y 6 la cantidad de FRAG representada por el peso como estimador de abundancia es mayor que en las muestras restantes, lo que indicaría la presencia de una mayor cantidad de especímenes malacológicos no identificables y mayor incidencia del proceso de fragmentación. En la Figura 6 se aprecia también que, utilizando el peso como estimador de abundancia, la M1 y 2 presentan la mayor frecuencia de restos identificables en la excavación. El peso de los restos no identificables en un depósito arqueológico puede ser de utilidad para reconocer diferencias en la distribución espacial de esta clase de materiales a nivel intrasitio y evaluar la acción de posibles agentes que hayan actuado de forma diferencial en el depósito.

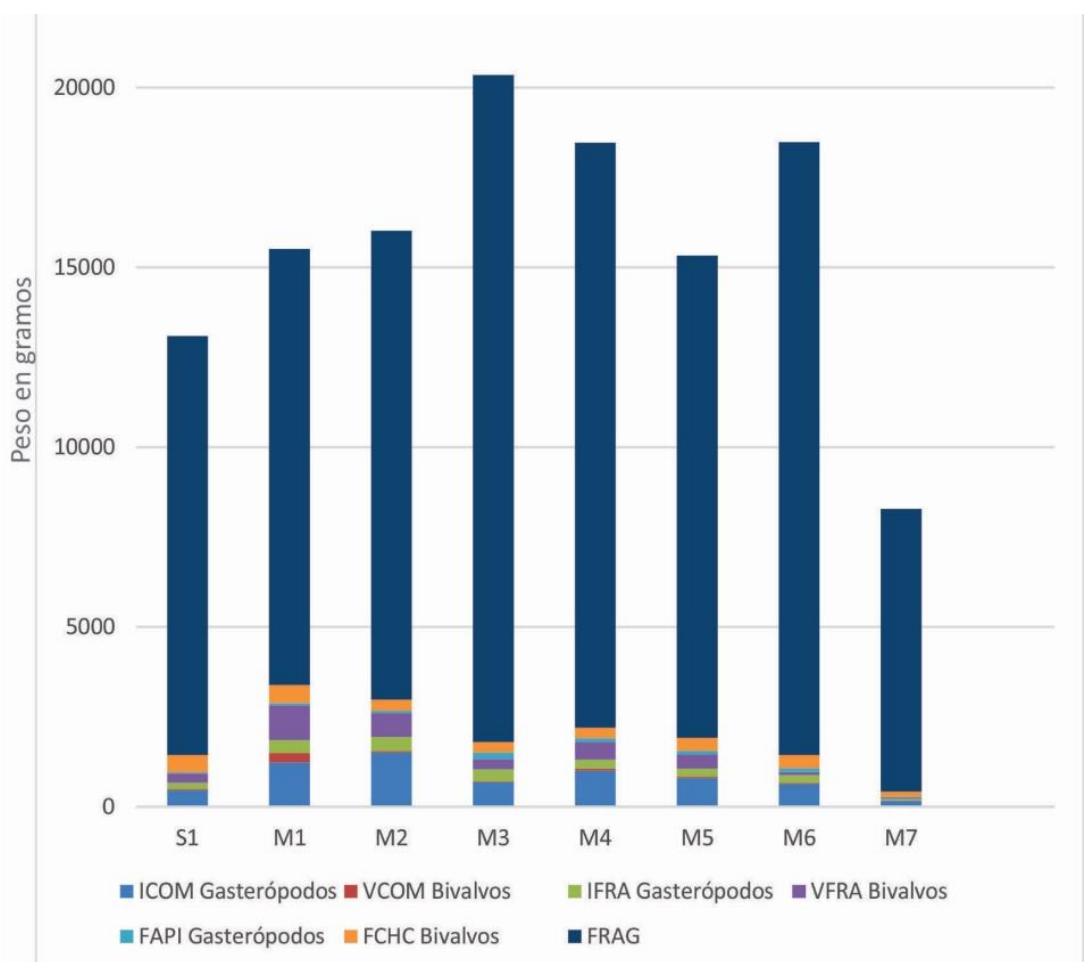

Figura 6. Peso de las clases malacológicas recuperadas -Gasterópodos y Bivalvos- en el conchero UNPA según las categorías de conservación de los restos. 
Distribución espacial de las especies predominantes de moluscos en sitios arqueológicos a lo largo del área CNSC

Fruto del estudio de los conjuntos arqueomalacológicos en la CNSC ha sido posible definir la existencia de un patrón de recolección de moluscos orientado en general hacia una especie, ya sea Nacella magellanica, Mytilus edulis o Aulacomya atra. Además se ha identificado que en general a la especie más representada le sigue en frecuencia alguna de las otras dos. Este patrón en la selección se esquematiza en la Figura 7, en la cual se presentan todos los sitios arqueológicos del área que cuentan con estudios de la malacofauna recuperada en contextos estratigráficos (especies e información cuantitativa de los conjuntos malacológicos) y en los cuales fue posible determinar el predominio de una especie en los conjuntos. Se incluyen concheros (Zubimendi et al. 2009, 2010, 2011, Zubimendi 2012, Hammond et al. 2009, Hammond 2015, Hammond y Zilio 2018) y dos sitios en alero con evidencias de procesamiento de moluscos: Alero el Oriental y Alero 4 (Ambrústolo et al. 2011, Ambrústolo y Ciampagna 2015).

En la Figura 7 se observa que en los sitios del golfo San Jorge las especies predominantes corresponden a Nacella magellanica. En este sector las costas abiertas y de alta energía serían más favorables para el desarrollo de especies de gasterópodos como Nacella sp. que puede adherirse más fuertemente a los sustratos rocosos que las especies de mitílidos. En la localidad Cabo Blanco, así como en los concheros ubicados en el sector de la ría Deseado y en las localidades al sur de la ría, no se observa una tendencia o patrón en la selección de una determinada especie de molusco utilizada como alimento, sino que existe variabilidad entre los conjuntos arqueomalacológicos que conforman los sitios.

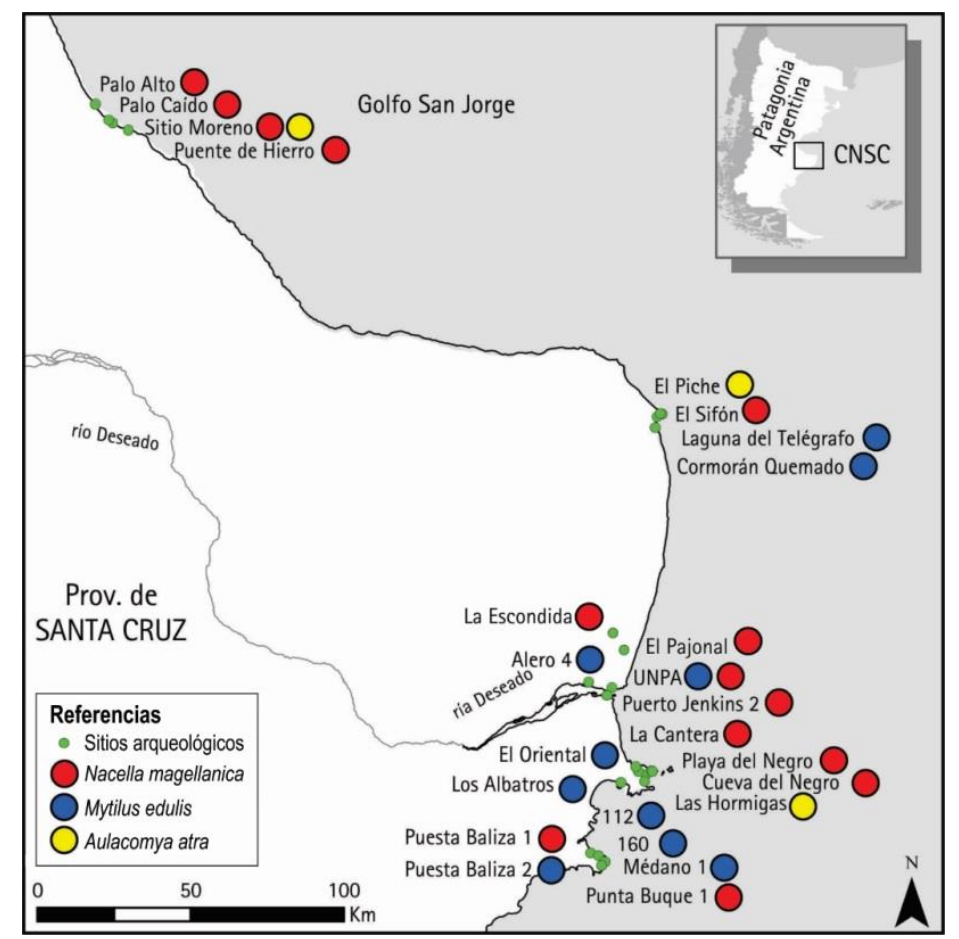

Figura 7. Representación de las especies predominantes en sitios arqueológicos de la CNSC que disponen de datos cuantitativos de los conjuntos arqueomalacológicos. 
En la Figura 8 se presentan los sitios que disponen de estudios cuantitativos de los conjuntos arqueomalacológicos y también de fechados radiocarbónicos asociados. Esta información proviene del presente trabajo y de artículos ya publicados (Tabla 1; Moreno 2008, Castro et al. 2010, Ambrústolo et al. 2011, Zubimendi et al. 2009, 2010, 2011, Zubimendi 2012, Ambrústolo y Ciampagna 2015, Hammond 2015, Hammond y Zilio 2018). Las dataciones radiocarbónicas se calibraron con el software OxCal 4.3 (Bronk Ramsey 2017). La calibración se realizó en años AP con dos desvíos estándar, empleando la curva para el Hemisferio Sur (SHCal13; Hogg et al. 2013).

OxCal v4.3.2 Bronk Ramsey (2017); r:5 SHCal13 atmospheric curve (Hogg et al 2013)

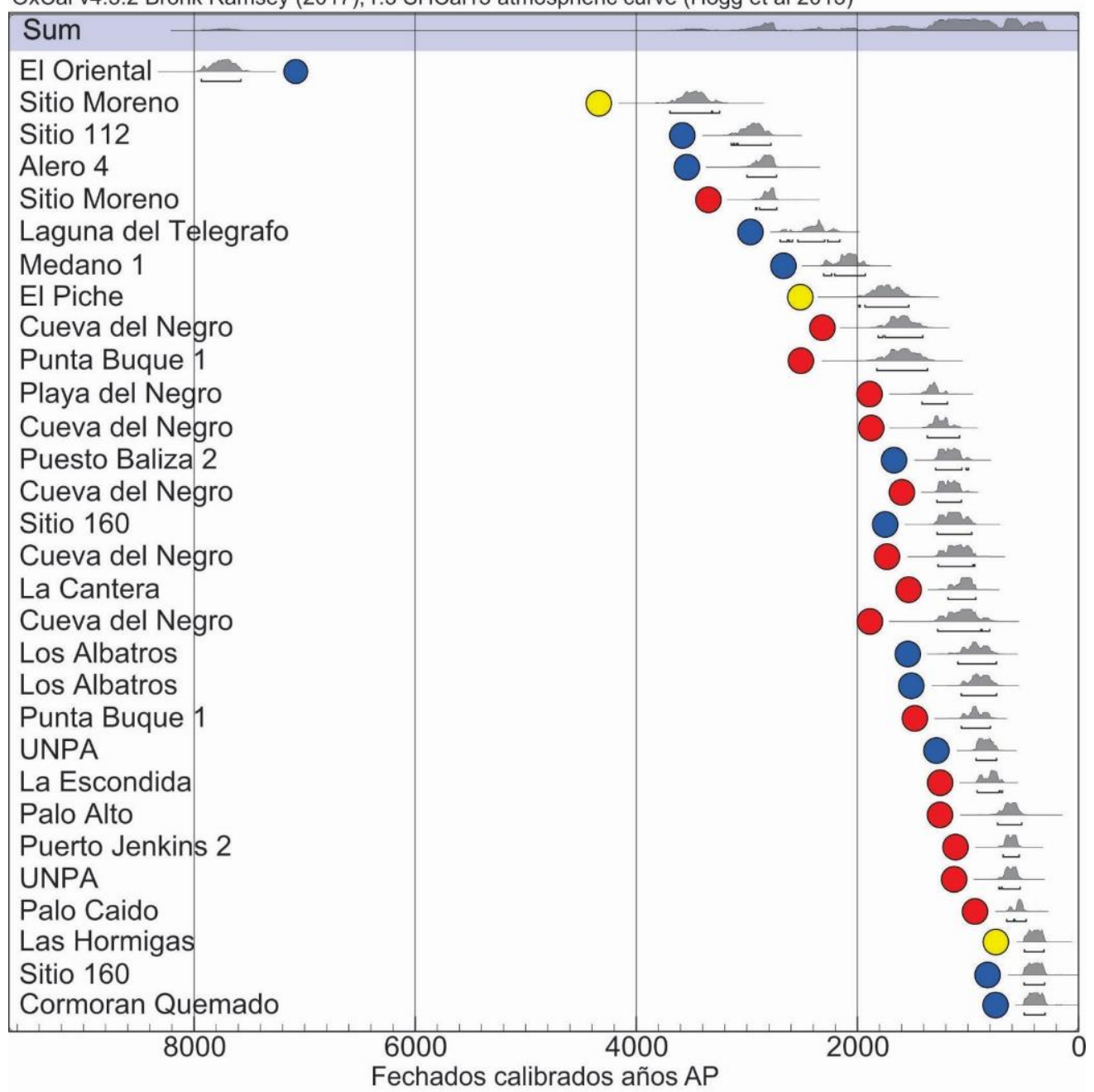

Figura 8. Sitios arqueológicos con datos cuantitativos de los conjuntos arqueomalacológicos y fechados radiocarbónicos en la CNSC. En colores se representan las especies de moluscos predominantes en cada uno de los sitios; Rojo: Nacella magellanica; Azul: Mytilus edulis; Amarillo: Aulacomya atra.

A partir de la figura se observa que la especie Nacella magellanica es la que predomina en la mayor cantidad de contextos (50\%), a esta le sigue Mytilus edulis (40\%) y finalmente Aulacomya atra (10\%). Se interpreta que no existe una tendencia temporal en cuanto a la selección predominante de una de las tres especies malacológicas con mayor valor alimenticio a través del tiempo. En este sentido, la predominancia de 
especies en los diferentes sitios no respondería a un patrón cronológico, el cual se podría relacionar con cambios ambientales que hayan repercutido o afectado la ecología de las especies y en consecuencia, su disponibilidad para los grupos humanos. Por lo contrario, la predominancia de una u otra especie en los concheros, respondería a un patrón espacial relacionado con la disponibilidad o mayor abundancia de determinadas especies de moluscos en los intermareales a lo largo del litoral marítimo.

Estudios tafonómicos de los exoesqueletos de moluscos

A partir del año 2011 comenzó a desarrollarse un programa sistemático de análisis tafonómico de los exoesqueletos de moluscos recuperados de las excavaciones en concheros (Tabla 1). Se analizó la presencia de evidencias y modificaciones generadas por diversos agentes antrópicos, biológicos, físico-geológicos y químicos (Hammond 2015). El objetivo de esta aproximación fue aportar a la comprensión acerca de las ocupaciones humanas, de los agentes y los procesos de formación de sitio, reconocer posibles depósitos naturales, evaluar la integridad de los registros y aportar a la discusión acerca de la tafonomía regional en el área de estudio.

En la mayoría de los sitios (Tabla 1), las conchas de moluscos se hallan alteradas térmicamente (se identificaron evidencias de quemado, carbonizado y calcinado). En el Sitio 112 los exoesqueletos presentan evidencias de calcinación y malas condiciones de preservación, en el resto de los sitios son más comunes los signos de quemado (Hammond 2015, Hammond y Zilio 2017, 2018, Hammond y Ciampagna 2019). Este proceso puede deberse al descarte de los restos en las áreas de combustión de los sitios o como se ha planteado debido a la ocurrencia de procesos de reencendido en las áreas de combustión que podrían estar relacionados con la presencia de signos de alteración térmica a temperaturas elevadas de los exoesqueletos. La preparación de los alimentos, la caída accidental de los restos al fuego o el empleo de los exoesqueletos como combustible también pueden generar la modificación de los restos por acción térmica (Hammond y Ciampagna 2019).

Otro de los procesos más representados es la fragmentación, que influye en la identificabilidad de los restos arqueomalacológicos. Los índices más altos de fragmentación se registraron en los sitios UNPA, el Sitio 112 y en el sitio Médano 1. En el primero los moluscos se encontraban muy compactados y fracturados en una matriz sedimentaria con alta humedad y contenido de materia orgánica. En el Sitio 112, la fragmentación de los exoesqueletos está influenciada por el debilitamiento producto de su exposición a altas temperaturas. La preservación de las conchas está determinada también por las características de la estructura calcárea, la forma, el tamaño, la escultura y el grosor de la misma, entre otras características (por ejemplo Figura 6).

Otra de las variables que se analizó es la preservación del color original de los exoesqueletos. Se ha establecido que la pérdida del color original de las conchas se relaciona especialmente con la ocurrencia de otros procesos como la abrasión debido al 
movimiento de partículas sedimentarias y del roce de las conchas entre sí, la corrosión que genera la disolución del carbonato cálcico debido a procesos químicos producidos en el ambiente (Gutiérrez Zugasti 2008a) y la alteración térmica. En los conjuntos de superficie el proceso de calcinación solar puede también alterar significativamente las superficies de las conchas.

En dos concheros del área, los sitios Las Hormigas (Tabla 1) y Los Albatros (Zubimendi y Hammond 2009) se registraron altos porcentajes de valvas de Aulacomya atra y Mytilus edulis con preservación del periostraco. La preservación de esta membrana proteica se asocia en estos casos a sitios en los que la matriz sedimentaria está compuesta por sedimentos eólicos finos (dunas y mantos eólicos), en los cuales es factible que se produzca una rápida cobertura de los restos arqueológicos debido principalmente a la dinámica eólica de la zona. Sin embargo, la preservación del periostraco en contextos estratigráficos, estará también determinada por las condiciones de la matriz sedimentaria como la presencia de humedad, el contenido orgánico, el $\mathrm{pH}$, la temperatura y aireación, entre otros, que pueden provocar también su deterioro y/o destrucción (Hammond 2014).

En ocho de los sitios presentados en la tabla 1 se registró la incidencia del proceso de bioerosión en los exoesqueletos, aunque en porcentajes bajos (entre 0,3 y 5 \%). Las evidencias de acción de organismos incrustantes y bioerosionadores en los conjuntos aporta información ecológica de los intermareales que fueron explotados por las poblaciones pasadas, y además, las marcas dejadas por estos organismos deben ser analizadas y discriminadas de aquellas generadas por acción cultural (por ejemplo, perforaciones).

Los estudios de formación de sitios concheros realizados en el área de estudio han permitido plantear que el agente antrópico fue el principal involucrado en la formación de los sitios y en la adquisición, el transporte y la acumulación de los arqueosedimentos, principalmente de los moluscos consumidos en la dieta. Hoy día el agente antrópico también genera modificaciones sobre el registro arqueológico, por ejemplo a partir de la construcción de caminos y vías de circulación, del coleccionismo, de la extracción de sedimentos para la construcción o indirectamente a través de la introducción de ganado que altera los sitios. Entre los procesos naturales en el área de estudio, el agente más importante en la formación y transformación de sitios a cielo abierto es el eólico, que puede generar la movilización y redepositación de materiales, la eliminación de restos pequeños, abrasión, entre otros. Además, los procesos hídricos y la acción de animales como roedores, armadillos y pingüinos tienen muchas veces importantes impactos en la integridad de los concheros (Hammond et al. 2016).

Un hecho importante en concheros cercanos a líneas de costas es la distinción entre depósitos naturales de culturales. Existen características que podrían indicar cuándo una acumulación, conformada principalmente por conchas de moluscos, es natural. Entre ellas podrían mencionarse que éstas se encuentran con frecuencia en terrazas 
levantadas o formas de relieve antiguas. Los depósitos pueden constar de una sola especie seleccionada o de una gama de especies (tanto comestibles como no comestibles) y de tamaños, debido a la acción y el movimiento del agua que produjo la depositación (Bowdler 2014). Las depositaciones naturales generalmente se hallan bien estratificadas y muestran rasgos sedimentarios debidos a su depositación por la acción del agua (Bowdler 2014). Estas acumulaciones mostrarán además signos de daños relacionados con la acción de las olas y el movimiento del agua, que puede generar superficies erosionadas, redondeo y desgaste de la escultura de las conchas y a su vez, el impacto y la ruptura de los restos. Los moluscos no presentarán signos de haber estado expuestos al fuego o daños debido a la apertura deliberada de las valvas. Será poco probable hallar valvas pareadas, huesos de fauna con signos de procesamiento y materiales culturales como fogones y artefactos de piedra asociados, así como lentes de cenizas y carbones o matrices sedimentarias con alto contenido de materia orgánica, tal como se observa en concheros arqueológicos. Otras causas naturales por las que pueden generarse acumulaciones de exoesqueletos es por la acción de animales que se nutren de moluscos o que pueden transportar los moluscos (que utilizan como alimento) hacia el terreno, como por ejemplo aves, zorros, pinnípedos, entre otros. De esta manera, los estudios tafonómicos de los restos arqueomalacológicos de sitios costeros, son necesarios para evaluar cuidadosamente los orígenes de los restos faunísticos en los sitios y los agentes involucrados en su transporte y depositación (Erlandson y Moss 2001).

En la CNSC un caso en el cual a partir de los análisis tafonómicos y de la estructura del sitio se pudo discriminar conchas aportadas naturalmente fue en el conchero UNPA ubicado en Puerto Deseado (Figura 1 y 7). Se registraron diversas conchas de Pareuthria fuscata con evidencia de abrasión marina, redondeo y pérdida del color original en diferentes cuadrículas del sitio. Esta característica, además de la observación de exoesqueletos de esta especie de molusco en otros sectores cercanos al sector de excavación sin evidencias de ocupación humana, nos permitió interpretar que la presencia de estos ejemplares era previa a la ocupación del sitio, debido a que los mismos formaban parte del cordón natural de rodados litorales sobre el cual se emplazó posteriormente el conchero (Hammond y Zilio 2017).

Estructura de los depósitos de conchero en la CNSC: evidencias estratigráficas

Teniendo en cuenta la geometría y la fábrica de los depósitos es posible realizar una clasificación de los diferentes sitios excavados a partir de la distribución de los materiales en estratigrafía, la cual puede servir para predecir otras potenciales características de los sitios, como por ejemplo cuestiones de integridad, preservación de los materiales, resolución (Binford 1981), entre otras (Tabla 2).

Los depósitos tabulares muy dispersos y dispersos (Tabla 2), presentan en general una fábrica abierta de tipo matriz sostenida y una muy baja a baja densidad de arqueosedimentos. En otros depósitos se identificaron lentes arqueológicas 
individuales, con fábricas de tipo clasto sostenidas y con variabilidad en la densidad de exoesqueletos de moluscos, estos se denominaron depósitos lenticulares dispersos y depósitos lenticulares densos (Tabla 2; Hammond 2015).

Los depósitos tabulares masivos conciernen a depositaciones de materiales arqueológicos, principalmente exoesqueletos de moluscos, de más de $30 \mathrm{~cm}$ de potencia (Tabla 2; Figura 2-b), correspondientes a episodios sucesivos de depositación (alta tasa o ritmo de depositación) producto de las actividades humanas en el espacio e influenciados por la baja tasa sedimentaria local. Estos sitios serían consecuencia de la repetición de actividades y la depositación y descarte de materiales en el mismo lugar o en lugares similares con un considerable solapamiento a lo largo del tiempo, generandose depósitos de grano grueso. Este tipo de depósitos se caracteriza por la pérdida de resolución (Tabla 2).

\begin{tabular}{|c|c|c|c|c|}
\hline $\begin{array}{c}\text { Clasificación } \\
\text { de los } \\
\text { depósitos } \\
\end{array}$ & Geometría & Fábrica & $\begin{array}{c}\text { Otras } \\
\text { características }\end{array}$ & Ejemplo \\
\hline $\begin{array}{l}\text { Depósito } \\
\text { tabular muy } \\
\text { disperso }\end{array}$ & Tabular & $\begin{array}{l}\text { Matriz sostenida. } \\
\text { Baja densidad de } \\
\text { materiales, } \\
\text { dispersos. }\end{array}$ & \multirow[t]{2}{*}{ Baja resolución } & $\begin{array}{l}\text { Puesto Baliza } 1 \\
\text { El Pajonal }\end{array}$ \\
\hline $\begin{array}{l}\text { Depósito } \\
\text { tabular } \\
\text { disperso }\end{array}$ & Tabular & $\begin{array}{l}\text { Matriz sostenida. } \\
\text { Densidad madia de } \\
\text { materiales, } \\
\text { dispersos. }\end{array}$ & & $\begin{array}{l}\text { Puesto Baliza } 2 \\
\text { Playa del } \\
\text { Negro }\end{array}$ \\
\hline $\begin{array}{l}\text { Depósito } \\
\text { tabular } \\
\text { masivo }\end{array}$ & Tabular & $\begin{array}{l}\text { Clasto sostenida. } \\
\text { Muy alta densidad } \\
\text { de restos que } \\
\text { ocupan más de } 30 \\
\text { cm de potencia. }\end{array}$ & $\begin{array}{l}\text {-Fragmentación } \\
\text {-Compactación } \\
\text {-Dificultad de } \\
\text { discriminar } \\
\text { eventos de } \\
\text { descarte } \\
\text {-Baja resolución } \\
\text {-Palimpsestos } \\
\text { acumulativos } \\
\text { (Bailey, 2007). }\end{array}$ & $\begin{array}{l}\text { Punta Buque } 1 \\
\text { (sondeo } 2 \text { ) } \\
\text { Médano } 1\end{array}$ \\
\hline $\begin{array}{l}\text { Depósito } \\
\text { lenticular } \\
\text { disperso }\end{array}$ & Lenticular & $\begin{array}{l}\text { Clasto sostenida. } \\
\text { Baja densidad de } \\
\text { restos conforman } \\
\text { la lente discreta. }\end{array}$ & \multirow[t]{2}{*}{$\begin{array}{l}\sim \text { Mayor } \\
\text { resolución } \\
\text {-Buena integridad }\end{array}$} & $\begin{array}{l}\text { Punta Buque } 1 \\
\text { (sondeo } 1 \text { ) }\end{array}$ \\
\hline $\begin{array}{l}\text { Depósito } \\
\text { lenticular } \\
\text { denso }\end{array}$ & Lenticular & $\begin{array}{l}\text { Clasto sostenida. } \\
\text { Alta densidad de } \\
\text { restos conforman } \\
\text { la lente discreta. }\end{array}$ & & $\begin{array}{l}\text { Las Hormigas } \\
\text { Sitio } 112 \\
\text { Sitio } 160 \\
\text { UNPA }\end{array}$ \\
\hline
\end{tabular}

Tabla 2. Clasificación estructural de los concheros.

A nivel estructural fue posible observar que las diferencias entre los depósitos están dadas principalmente por el agente antrópico, el cual fue el principal responsable del aporte de los materiales arqueológicos que componen los sitios. La acción de otros agentes como el eólico, el hídrico y las modificaciones generadas en los concheros por los animales generan procesos que afectan fundamentalmente la integridad de los 
contextos, por ejemplo a partir de la movilización, mezcla, depositación-redepositación de restos, compactación o desplazamientos verticales u horizontales y las condiciones de preservación de los arqueosedimentos (Hammond et al. 2016).

En cuanto a las condiciones geoquímicas de la matriz sedimentaria de concheros, se cuenta con información obtenida a partir del análisis en diez sitios (Hammond 2015, Hammond et al. 2016). Los valores de $\mathrm{pH}$ presentan un promedio de 8,3, por lo que se definen como medianamente alcalinos. En general, la abundancia de carbonato de calcio que conforma los exoesqueletos de moluscos produce la formación de un $\mathrm{pH}$ neutro o medianamente alcalino, asociado en este caso a matrices constituidas principalmente por arena fina, sustratos salobres cercanos al litoral marítimo y clima árido. Los ambientes alcalinos son favorables para la preservación de muchos materiales orgánicos, como restos óseos y arqueobotánicos (Claassen 1998, Orquera y Piana 2000). Los valores de materia orgánica obtenidos son bajos, entre 1,12\% y 1,44\% y en general no muestran variaciones en profundidad que puedan evidenciar procesos pedológicos. A su vez, el $\mathrm{pH}$ puede estar relacionado con las cantidades crecientes de desechos orgánicos introducidos por las personas durante la ocupación (Stein 1987), aunque se debe evaluar cuidadosamente este aspecto, ya que la fuente de procedencia de la materia orgánica puede ser variable (Stein 1992).

Estudios biométricos de los exoesqueletos de moluscos

Se han realizado estudios biométricos sobre 10.718 exoesqueletos de moluscos recuperados en concheros, correspondientes a las especies Nacella magellanica, Mytilus edulis, Aulacomya atra y Perumytilus purpuratus (Zubimendi 2012, Hammond y Zilio 2016a, 2018). Las muestras proceden de 18 concheros excavados en la CNSC, de los cuales 17 cuentan con fechados radiocarbónicos. A partir de los análisis se registró una tendencia temporal que indica una disminución del tamaño medio de los moluscos a través del tiempo, desde hace ca. 3000 años AP hasta ca. 300 años AP (Hammond y Zilio 2016a).

Se ha propuesto que la reducción en el tamaño de los exoesqueletos podría estar relacionada con la explotación reiterada de los moluscos a través del tiempo y/o con la ocurrencia de un proceso de intensificación mayor que involucró el uso de estos recursos (Zilio 2017). En referencia a la primera posibilidad, se podría haber incrementado la frecuencia en la recolección de los moluscos, lo que habría afectado al tiempo necesario de recuperación de los invertebrados en las plataformas de abrasión para volver a conseguir un tamaño adecuado para el consumo. En este caso, se postula un proceso de intensificación en el uso del recurso y no una sobreexplotación del mismo. La intensificación y/o explotación reiterada de los moluscos a través del tiempo habría generado una leve disminución en el tamaño de los exoesqueletos, no obstante el recurso no se agotó en ningún momento (Hammond y Zilio 2016a). 
Las especies de moluscos que fueron seleccionadas por los grupos humanos con fines alimenticios en la CNSC son desde el punto de vista ecológico, plásticas o euritópicas (tolerantes a variaciones de temperatura, salinidad y a una amplia gama de condiciones ambientales; Gordillo com pers.). Además, presentan un muy amplio rango de distribución dentro de la Provincia Malacológica Magallánica, por lo que los cambios menores de temperatura durante el Holoceno tardío en estas latitudes, probablemente, no hayan afectado al tamaño de los moluscos, siendo las comunidades bentónicas de estas especies más o menos estables.

Un caso llamativo está representado por los conjuntos arqueomalacológicos recuperados en sitios emplazados en torno a lagunas ubicadas a $20 \mathrm{~km}$ al norte de la ciudad de Puerto Deseado y distantes aproximadamente entre 2 y $5 \mathrm{~km}$ desde la línea de litoral marino actual. De estos sitios, denominados La Escondida y El Pajonal, el primero de ellos fue datado y se obtuvo un fechado de $920 \pm 50$ años AP (LP-3359; Tabla 1). En estos contextos los conjuntos arqueomalacológicos están formados casi exclusivamente por conchas de Nacella magellanica y La Escondida presenta las conchas de este gasterópodo con el tamaño más grande registrado hasta el momento para sitios concheros en la costa norte de Santa Cruz. Los tamaños obtenidos en El Pajonal también se ubican entre los más altos para el área de estudio (Hammond y Zilio 2018). Las medidas biométricas que se conocen para la CNSC provienen de exoesqueletos de moluscos recuperados en concheros ubicados en la franja de costa (Hammond y Zilio 2016a), de esta manera, surge el interrogante de si el tamaño promedio de las conchas recuperadas en los sitios asociados a lagunas, en comparación a aquellas registradas en concheros cercanos al litoral marítimo, podría deberse a una selección de los ejemplares por tamaño, teniendo en cuenta que las mismas se trasladaron hasta el sitio desde una distancia mínima de $2 \mathrm{~km}$ desde la costa. Como plantea Waselkov (1987), el costo de transportar a grandes distancias los recursos malacológicos es alto, debido a que la proporción de carne comestible en relación al peso total del molusco es generalmente baja. Se considera que posiblemente en estos casos se habrían seleccionado individualmente los moluscos durante la recolección y trasportado hacia las lagunas los ejemplares de mayor tamaño y contenido de carne con el fin de obtener el máximo de alimento en cada traslado (Hammond y Zilio 2018).

Obtención y procesamiento de los recursos malacológicos por los grupos humanos

Las estrategias de recolección de moluscos empleadas habrían sido relativamente sencillas. La recolección manual por individuos en "racimos" o en grupos de especies sésiles que viven adheridas entre sí, como por ejemplo de Aulacomya atra y Mytilus edulis, habría sido uno de los métodos mayormente empleados en el pasado (Orquera y Piana 1999). Para la recolección manual de individuos de especies móviles, como aquellos de la especie Nacella magellanica, se habrían empleado instrumentos para desprender los moluscos del sustrato duro al que viven adheridos. Los instrumentos podrían haber estado representados por artefactos líticos (Pailler et al. 2007, Gutiérrez Zugasti y González Morales 2010), por palos espatulados tal como fue observado en los 
grupos Selk'nam de Tierra del Fuego, o por algún otro tipo de artefacto de materia prima resistente, como por ejemplo hueso. En este sentido, no se descarta la implementación de otros métodos de recolección por las poblaciones, aunque no se cuenta con evidencias que apoyen esta posibilidad.

Durante el estudio de las muestras arqueomalacológicas recuperadas en estratigrafía se registró que un porcentaje de entre un $12 \%$ y un $48,5 \%$ de las conchas de Nacella magellanica presentaban marcas particulares que se caracterizaban por la presencia de roturas con formas redondeadas u ovaladas, de tamaños variables, con bordes irregulares y en ocasiones algo angulosos, y signos de impacto con consecuente rotura de la estructura (Figura 9).
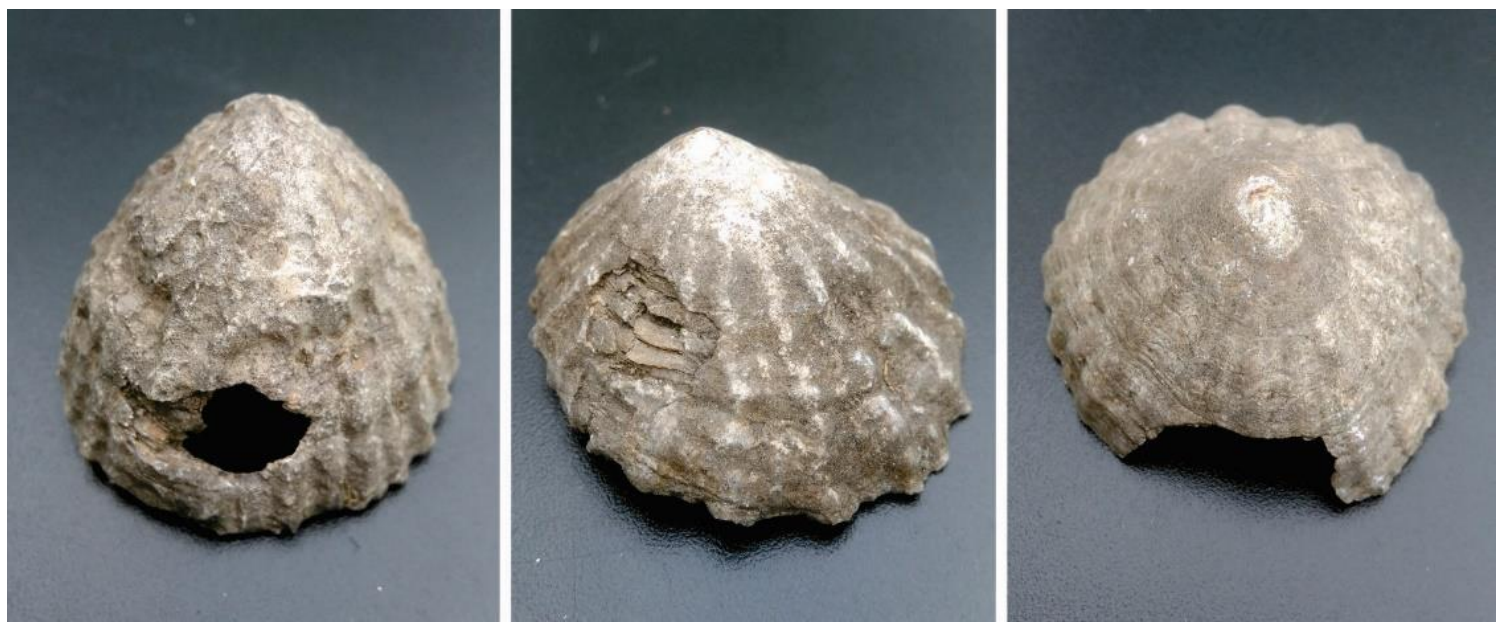

Figura 9. Tipos de modificaciones identificadas en conchas de Nacella magellanica. De izquierda a derecha: rotura, signo de impacto y rotura del margen.

A partir de estos resultados se decidió desarrollar un programa experimental con el fin de evaluar la/las posibles causas y el agente responsable de estas modificación. Este programa experimental permitió relacionar las modificaciones observadas en las conchas y el uso de un tipo particular de instrumento que se identifica comúnmente en los sitios concheros del área y en colecciones arqueológicas (Zilio et al. 2018b), y que habría sido empleado para la recolección de esta especie de gasterópodo. Estos instrumentos se tratan de rodados líticos con morfología alargada, algunos con presencia de un extremo biselado, y en otros casos, solo con un extremo o borde redondeado naturalmente, no formatizado. Los estudios experimentales permitieron interpretar que las roturas $\mathrm{y} / \mathrm{o}$ signos de impacto en los conjuntos arqueomalacológicos podrían ser consecuencia de acciones desarrolladas por las poblaciones humanas durante la recolección de los moluscos (Hammond y Zilio 2016b).

Por otro lado, y con el objetivo de evaluar la acción de la alteración térmica y las modificaciones generadas en los exoesqueletos de Nacella magellanica se desarrolló un programa experimental de alteración térmica sobre ejemplares de esta especie con el objetivo de identificar rasgos diagnósticos y modificaciones como consecuencia del 
proceso que aporten a la discusión sobre los efectos de la exposición térmica de los moluscos recuperados en sitios arqueológicos. Siete muestras, de 20 exoesqueletos cada una, se sometieron a temperaturas sucesivas desde $\operatorname{los} 0^{\circ} \mathrm{C}$ a $\operatorname{los} 700^{\circ} \mathrm{C}$. Los siete conjuntos fueron introducidos en el mismo momento en la mufla que se programó para que cada $100^{\circ} \mathrm{C}$ permanezca en la temperatura deseada durante 15 minutos. Una vez extraídas del horno las conchas fueron pesadas para calcular el porcentaje de pérdida de peso producido por la quema. Se llevó a cabo el análisis estructural, cromático y textural sobre cada una de las muestras. A partir de la experimentación controlada se logró aislar una serie de modificaciones y rasgos que se generan en las conchas de Nacella sp. como producto de la quema. Estas transformaciones se relacionan principalmente con cambios en la coloración, modificaciones texturales, daños estructurales y un leve descenso paulatino del peso de los restos a medida que estas se exponen a temperaturas más elevadas. Los cambios registrados fueron apreciados claramente a partir de $\operatorname{los} 300^{\circ} \mathrm{C}$, temperatura a la cual se registraron de forma notoria las modificaciones en la coloración y el desarrollo de microfisuras contiguas en la superficie interna de las conchas. Se realizó una comparación de los resultados de la experimentación con muestras de concheros del área que permitió inferir por ejemplo que en los concheros Las Hormigas y el Sitio 112 las conchas no habrían estado expuestas a temperaturas superiores a $300^{\circ} \mathrm{C}$ de acuerdo a las características colorimétricas, texturales y a los daños registrados. En el Sitio 160 parte del conjunto podría haber estado expuesto a temperaturas de hasta alrededor de $400^{\circ} \mathrm{C}$ (Hammond y Ciampagna 2019).

\section{Consideraciones finales}

En diversos contextos arqueológicos en ambientes litorales los restos de moluscos que fueron utilizados por las poblaciones pasadas representan un tipo de registro abundante, y que además en general se preservan en buenas condiciones debido a la resistencia de los exoesqueletos. En este trabajo se presentó una síntesis de los estudios arqueomalacológicos de conjuntos recuperados en concheros que aportan a la comprensión de este tipo de registros costeros y nos permiten conocer acerca de diversas características de las poblaciones que ocuparon el área de la CNSC en el pasado, tales como la subsistencia, los modos de ocupación del espacio y las formas de obtención de los recursos malacológicos. Por otro lado, los análisis han servido para la interpretación de los procesos de formación del registro arqueológico y para dar cuenta de la importancia de evaluar el contexto ambiental, ecológico y geomorfológico regional a la hora de interpretar los registros costeros conformados por moluscos.

A partir de los análisis se han identificado los principales taxones con valor alimenticio para las poblaciones pasadas, los que en algunos casos presentan evidencias de procesamiento y acción antrópica. Además se han registrado otras especies "acompañantes" que aportan información sobre la formación de los depósitos costeros y las condiciones ambientales del área. La identificación de los procesos 
tafonómicos principales que actúan sobre los exoesqueletos de moluscos y sobre los depósitos en general ha posibilitado reconocer que los agentes principales involucrados en la formación de los concheros son similares a lo largo del área de estudio.

Los resultados alcanzados hasta el momento a través de varios años de investigación han permitido generar un cuerpo de información relevante acerca de la arqueomalacología de concheros en el área de estudio y para la generación de expectativas arqueológicas respecto de la incidencia de ciertos agentes y procesos en la formación, preservación y modificación actual de los contextos arqueológicos, y en consecuencia, para la interpretación de los depósitos. En una agenda futura se espera avanzar en nuevas líneas de análisis con el fin de complementar y enriquecer los resultados obtenidos, como por ejemplo, el desarrollo de estudios de estacionalidad en la explotación de los recursos malacológicos, de isótopos estables $\left(\delta^{13} \mathrm{C}\right.$ y $\left.\delta^{15} \mathrm{~N}\right)$ para evaluar el papel de los moluscos en las dietas humanas, entre otros.

Agradecimientos: a los miembros del proyecto Arqueología de la costa norte de Santa Cruz. A los editores del Dossier por la invitación a participar de la publicación. A los editores de la revista y a los evaluadores quienes mediante sus comentarios y sugerencias permitieron mejorar el artículo. Al Consejo Nacional de Investigaciones Científicas y Técnicas (CONICET) por las becas doctorales y posdoctoral de la autora.

\section{Bibliografía citada}

Aguirre, M. L.

2003 Late Pleistocene and Holocene palaeoenvironments in Golfo San Jorge, Patagonia: molluscan evidence. Marine Geology 194(1): 3-30.

Aguirre, M. L., y E. A. Farinati

2000 Moluscos del Cuaternario marino de la Argentina. Boletín de la Academia Nacional de Ciencias 64: 235-333.

Aguirre, M. L., Richiano, S., Álvarez, M. F., y C. Eastoe 2009 Malacofauna Cuaternaria del litoral norte de Santa Cruz (Patagonia, Argentina). Geobios 42(4): 411-434.

Allison, L.

1965 Organic Corbon. En Methods of Soils Analysis.Chemical and Microbiological Properties, C. Black (ed.), pp. 1367-1378. American Society of Agronomy, Madison, Wisconsin. 
Álvarez Fernández, E.

2009 La explotación de los moluscos marinos en la Cornisa Cantábrica durante el Gravetiense: primeros datos de los niveles E y F de La Garma A (Omoño, Cantabria). Zephyrus 60: 43-58.

Ambrústolo, P. y M. L. Ciampagna

2015 Alero 4 rock shelter, north coast of Deseado estuary (Patagonia, Argentina): Hunter-gatherer mobility strategies during the Late Holocene. Quaternary International 373: $17-25$.

Ambrústolo, P., Zubimendi, M. A., Ciampagna, M. L. y V. Trola

2011 Alero El Oriental: evidencias de las primeras ocupaciones de la costa norte de Santa Cruz (Patagonia, Argentina). Werke 14(1): 9-22.

Bailey, G. N.

2007 Time perspectives, palimpsests and the archaeology of time. Journal of Anthropological Archaeology 26(2): 198-223.

Balech, E. y M. D. Ehrlich

2008 Esquema biogeográfico del mar Argentino. Revista de Investigación en Desarrollo Pesquero (19): 45-75.

Bejega García, V.

2008 Composición y metodología de análisis de concheros aplicada a los castros litorales gallegos. En Actas de las I Jornadas de Jóvenes en Investigación Arqueológica: Dialogando con la cultura material, pp. 247-254. Compañía Española de Reprografía y Servicios.

Bejega García, V., Fernández Rodríguez, C. y E. González Gómez de Agüero 2010 La Arqueomalacología: una introducción al estudio de los restos de moluscos recuperados en yacimientos arqueológicos. Iberus 1: 1-10.

Beretta, J. M., L. Corinaldessi y A. Castro.

2011 Recursos marinos vs. recursos terrestres: análisis arqueofaunístico en el sitio cueva del negro, costa norte de Santa Cruz. Arqueología (17): 137-160.

Binford, L. R.

1981 Bones: ancient men and modern myths. Academic Press, Nueva York.

Bowdler, $\mathrm{S}$.

2014 Shell Middens and Mollusks. En Archaeology in Practice: A Student Guide to Archaeological Analyses, J. Balme y A. Paterson (eds.), pp. 361-384. John Wiley \& Sons, Inc, Estados Unidos. 
Bronk Ramsey, C.

2017 Methods for Summarizing Radiocarbon Datasets. Radiocarbon 59(2): 1809-1833.

Campbell, G.

2007 Appendix G: the marine invertebrate remains. En Les fouilles du Yaudet en Ploulec'h, Cotes d'Armor, P. Galliou y B. Cunliffe (eds.). Disponible en http://www.arch.ox.ac.uk/research/research_projects/le_yaudet/appendices

Castro, A. S., Moreno, J. E., Andolfo, M. y M. A. Zubimendi

2001 Distribución espacial de sitios en la localidad de Punta Medanosa, Santa Cruz (Argentina). Relaciones de la Sociedad Argentina de Antropología XXVI: 303-322.

Castro, A., Moreno, J. E., Andolfo, M. A., Giménez, R., Peña, C., Mazzitelli, L., Zubimendi, M. A. y P. Ambrústolo

2003 Análisis distribucionales en la costa de Santa Cruz (Patagonia Argentina): alcances y resultados. Magallania 31: 69-94.

Castro, C., Zubimendi, M. A., Ambrústolo, P., Mazzitelli, L., Beretta, M., Ciampagna, L., Trola, V., Hammond, H., Zilio, L. y M. Plischuck

2010 Sitio Cueva del Negro: un caso de aprovechamiento intensivo de los recursos marinos en la costa norte de Santa Cruz (Patagonia Argentina). En Actas del XVII Congreso Nacional de Arqueología Argentina. Arqueología Argentina en el Bicentenario de la Revolución de Mayo, J. R. Bárcena y H. Chiavazza (eds.), Tomo 1, pp. 309-314. Facultad de Filosofía y Letras UNCuyo-CONICET, Mendoza.

Chaix, L. y P. Méniel

2005 Manual de Arqueozoología. Prehistoria Ariel, Francia.

Claassen, C.

1998 Shells. Cambridge University Press, Nueva York.

2000 Quantifying shell: comments on Mason, Peterson, and Tiffany. American Antiquity 65(2): 415-418.

Codignotto, J. O.

1997 Geomorfología y dinámica costera. El mar argentino y sus recursos pesqueros 1: 89105.

Erlandson, J. M.

1988 The role of shellfish in prehistoric economies: a protein perspective. American Antiquity 53(1): 102-109.

Erlandson, J. M. y M. L. Moss

2001 Shellfish feeders, carrion eaters, and the archaeology of aquatic adaptations. American Antiquity 66(3): 413-432. 
Favier Dubois, C. y F. Borella

2007 Consideraciones acerca de los procesos de formación de concheros en la costa Norte del golfo San Matías (Río Negro, Argentina). Cazadores-recolectores del Cono Sur. Revista de Arqueología 2: 151-165.

Ford, P. J.

1992 Interpreting the grain size distributions of archaeological shell. En Deciphering $a$ shell midden, J. K. Stein (ed.), pp. 283-325. Academic Press, San Diego, California.

Giovas, C.M.

2009. The shell game: analytic problems in archaeological mollusc quantification. Journal of Archaeological Science 36: 1557-1564.

Gordillo, S.

1998 Distribución biogeográfica de los moluscos holocenos del litoral argentinouruguayo. Ameghiniana 35(2): 163-180.

Glassow, M. A.

2000 Weighing vs. counting shellfish remains: a comment on Mason, Peterson, and Tiffany. American Antiquity 65(2): 407-414.

Gutiérrez Zugasti, I.

2008 Análisis tafonómico en arqueomalacología: el ejemplo de los concheros de la región cantábrica. Revista Krei 10: 53-74.

2008b La explotación de moluscos y otros recursos litorales en la región cantábrica durante el pleistoceno final y el Holoceno inicial. Tesis de Doctorado. Departamento de Ciencias Históricas. Universidad de Cantabria, España.

Gutiérrez Zugasti, F. y M. González

2010 New data on Asturian shell midden sites: the cave of Mazaculos II (Asturias, Northern Spain). Munibe 31: 110-118.

Hammond, $\mathrm{H}$.

2014 Taphonomic analysis of archaeomalacological assemblages: shell middens on the northern coast of Santa Cruz (Patagonia, Argentina). Intersecciones en Antropología Volumen especial 1: 21-34.

2015 Sitios concheros en la costa norte de Santa Cruz: su estructura arqueológica y variabilidad espacial en cazadores recolectores patagónicos. Tesis de Doctorado. Facultad de Ciencias Naturales y Museo. Universidad Nacional de La Plata, Argentina. 2018 Distribuciones espaciales de concheros en la costa norte de Santa Cruz, Patagonia Argentina: características del registro arqueológico y uso del espacio litoral por poblaciones cazadoras-recolectoras. Comechingonia 22(2): 81-111. 
Hammond, H., Aguinaga, M. C., Trola, V., Ciampagna, L., Bogan, S. Zubimendi, M. A. y P. Ambrústolo

2009 ¿Sitio arqueológico o concentración natural? Análisis de restos presentes en el sitio El Sifón, Cabo Blanco (Costa norte de Santa Cruz). En Entre pasados y presentes II: estudios contemporáneos en ciencias antropológicas, T. Bourlot, D. Bozzuto, C. Crespo, A. C. Hecht y N. Kuperszmit (eds.), pp. 341-353. Fundación de Historia Natural Félix de Azara, Buenos Aires.

Hammond, H., Zubimendi, M. A. y L. Zilio

2013 Composición de concheros y uso del espacio: aproximaciones al paisaje arqueológico costero en Punta Medanosa. Anuario de Arqueología 5: 67-84.

Hammond, H. y L. Zilio

2016a Cambios en el tamaño de exoesqueletos calcáreos de moluscos durante el holoceno tardío: arqueomalacología de concheros en la costa norte de Santa Cruz, Patagonia argentina. Arqueología Iberoamericana 32: 17-24.

2016b Experimentación del proceso de recolección de moluscos marinos en la costa patagónica: análisis de la especie Nacella magellanica y sus implicancias en la interpretación de muestras arqueomalacológicas. Comechingonia 20(2): 265-290.

$2017 \mathrm{El}$ aprovechamiento de vertebrados e invertebrados por cazadores recolectores en el estuario de la ría Deseado: el caso del conchero UNPA. Arqueología 23(3): 129-152.

2018 Entre lagunas y el mar: uso del espacio por cazadores-recolectores en un paisaje lagunar de la costa norte de Santa Cruz. Arqueología 24(1): 225-236.

Hammond, H., Zilio, L. y A. Castro

2016 Distribución, emplazamiento y procesos de formación del registro arqueológico en Punta Medanosa, costa norte de Santa Cruz. Intersecciones en Antropología Volumen especial 4: 61-74.

Hammond, H. y M. L. Ciampagna

2019 Estudio experimental de alteración térmica sobre exoesqueletos de moluscos marinos (Nacella magellanica) y sus implicancias para la interpretación de conjuntos arqueomalacológicos de concheros en Patagonia Argentina. Boletín de Arqueología Experimental, 13. Boletín de Arqueología Experimental. En prensa.

Hogg, A. G., Hua, Q., Blackwell, P. G., Niu, M., Buck, C. E., Guilderson, T. P., Heaton, T. J., Palmer, T. G., Reimer, P. J., Reimer, R. W., Turney, C. S. M. y S. R. H. Zimmerman 2013 SHCal13 Southern Hemisphere calibration, 0-50,000 cal yr BP. Radiocarbon 55(4): 1889-1903.

Jones, T. L. y J. R. Richman

1995 On mussels: Mytilus californianus as a prehistoric resource. North American Archaeologist 16(1): 33-58. 
Kidwell, S. M. y S. M. Holland

1991 Field description of coarse bioclastic fabrics. Palaios 6: 426-434.

Lasta, M. L., Ciocco, N. F., Bremec, C. y A. Roux

1998 Moluscos bivalvos y gasterópodos. El mar argentino y sus recursos pesqueros 2: 115142.

Mason, R. D., Peterson, M. L. y J. A. Tiffany

1998 Weighing vs. counting: measurement reliability and the California school of midden analysis. American Antiquity 63(2): 303-324.

2000. Weighing and counting shell: a response to Glassow and Claassen. American Antiquity 65(4): 757-761.

Mazzoni, E.

2000 Las formas del paisaje. En El gran libro de la Provincia de Santa Cruz, C. J. Godoy (ed.), pp. 140-170. Milenio Ediciones, Buenos Aires.

Medina, R., Aguirre, M., Codignotto, J., Richiano, S. y L. Mormeneo

2014 Geoformas, malacofauna y evolución costera durante el Holoceno en Ensenada Ferrer (Santa Cruz, Patagonia, Argentina). Revista de la Asociación Geológica Argentina 71(1): 69-81.

Moreno, E.

2008 Arqueología y etnohistoria de la Costa Patagónica Central en el Holoceno Tardío. Fondo Editorial Provincial, Secretaría de Cultura del Chubut, Chubut.

Moreno, E., Zangrando, A. F., Tessone, A., Castro, A. S. y H. Panarello

2011 Isótopos estables, fauna y tecnología en el estudio de los cazadores-recolectores de la costa norte de Santa Cruz. Magallania 39(1): 265-276.

Orquera, L. A. y E. L. Piana

1999 Arqueología de la región del Canal Beagle: Tierra del Fuego, República Argentina. Sociedad Argentina de Antropología, Buenos Aires.

2000 Composición de conchales de la costa del Canal Beagle (Tierra del Fuego, República Argentina) -Primera Parte-. Relaciones de la Sociedad Argentina de Antropología XXV: 249-274.

Pailler, Y., Dupont, C., Sparfel, Y. y A. Leroy

2007 Analyse fonstionnelle des galets biseautés du Médolithique à la fin du Néolithique dans I’Oquest de la France, la Grande-Bretagneet I Irlande. Bulletin de la Société préhistorique francaise 104(1): 31-54. 
Peacock, E.

2000 Assessing bias in archaeological shell assemblages. Journal of Field Archaeology 27(2): 183-196.

Serrand, N., Dupont, C. y C. Martin

2008 L archéomalacologie. Archéopages 22: 62-75.

Stein, J. K.

1987 Deposits for archaeologyst. En Advances in Archaeologycal Method and Theory, M. B. Schiffer (ed.), pp. 337-395. Academic Press, San Diego.

Stein, J. K.

1992 Organic matter in archaeological contexts. En Soils in archaeology, landscape and human Occupation, V. Holliday (ed.), pp. 193-216. Smithsonian Institution Press, Londres.

Thomas, K.D. y M.A. Mannino

2017. Making numbers count: Beyond minimum numbers of individuals (MNI) for the quantification of mollusc assemblages from shell matrix sites. Quaternary International 427: 47-58.

Waselkov, G. A.

1987 Shellfish gathering and shell midden archaeology. Advances in archaeological method and theory 10: 93-210.

Yesner, D. R.

1980 Maritime hunter-gatherers: ecology and prehistory. Current Anthropology 21(6): 727-750.

Zaixso, H. E. y A. Boraso de Zaixso

2013 Bentos. En Plan de manejo Reserva Provincial Ría Deseado, C. Torlaschi y Paula Cedrola (eds.), pp. 31-38. Consejo Agrario Provincial, Santa Cruz.

Zilio, L.

2017 La dinámica humana en la costa norte de Santa Cruz durante el Holoceno tardío: evidencias desde el registro mortuorio e isotópico. Revista Relaciones 42(2): 305-331.

Zilio, L., Gordón, F., Béguelin, M. y A. S. Castro

2014 Paleodietas humanas en el sur del Golfo San Jorge (provincia de Santa Cruz) a partir del análisis de isótopos estables. Revista Argentina de Antropología Biológica 16: 5164. 
Zilio, L., A. Tessone y H. Hammond

2018a Stable isotope ecology and human palaeodiet in the northern coast of Santa Cruz (Argentine Patagonia). International Journal of Osteoarchaeology 28: 305-317.

Zilio, L., S. Buus y H. Hammond

2018b La colección arqueológica "Pedro Dade" del Museo de La Plata. Revista del Museo de La Plata 3(2): 368-392.

Zubimendi, M. A.

2010 Estrategias de uso del espacio por grupos cazadores recolectores en la Costa Norte de Santa Cruz y su interior inmediato. Tesis de Doctorado. Facultad de Ciencias Naturales y Museo. Universidad Nacional de La Plata, Argentina.

2012 La variabilidad del registro arqueomalacológico en la costa norte de Santa Cruz (Patagonia argentina): resultados exploratorios a partir de estudios estratigráficos. Intersecciones en Antropología 13(2): 359-375.

Zubimendi, M. A., Castro, A. S. y J. E. Moreno

2004 Una aproximación hacia la definición de modelos de uso de la costa norte de Santa Cruz. Magallania 32: 209-220.

2005 El consumo de moluscos en la Costa Norte de Santa Cruz. Intersecciones en Antropología 6: 121-137.

Zubimendi, M. A. y H. Hammond

2009 Análisis de los restos malacológicos en el sitio Los Albatros, Bahía del Oso Marino (Provincia de Santa Cruz). En Arqueología de la Patagonia: una mirada desde el último confin, M. Salemme, F. Santiago, M. Álvarez, E. Piana, M. Vázquez y M. Mansur (eds.), pp. 865-877. Utopías, Ushuaia.

Zubimendi, M. A., L. Mazzitelli, L. Zilio, L. Ciampagna y V. Trola

2009 Informe Parcial de las excavaciones realizadas en octubre de 2009 en la localidad arqueológica Bahía Lángara. Sector del Golfo San Jorge, Costa Norte de Santa Cruz. Manuscrito inédito.

Zubimendi, M., Mazzitelli, L., Navarro, A. F., Zilio, L. y H. Hammond 2010 Primeras excavaciones en el sitio Palo Alto, Bahía Lángara, costa norte de Santa Cruz. En Actas del XVII Congreso Nacional de Arqueología Argentina. Arqueología Argentina en el Bicentenario de la Revolución de Mayo, J. R. Bárcena y H. Chiavazza (eds.), Tomo 3, pp. 2011-2016. Facultad de Filosofía y Letras UNCuyo-CONICET, Mendoza.

Zubimendi, M. A., Ambrústolo, P., Beretta, M., Mazzitelli, L. Hammond, H., Ciampagna, M. L., Zilio, L., Plischuk M. y A. S. Castro

2011 Sitio Cueva del Negro: Un caso de aprovechamiento intensivo de los recursos marinos en la Costa Norte de Santa Cruz (Patagonia Argentina). Revista de Estudios Marítimos y Sociales 4: 51-62 